Portland State University

PDXScholar

\title{
Facility Location Model for Free Clinics to Address Healthcare Disparities in Portland, OR
}

Mikhaela C. Sample

Portland State University

Follow this and additional works at: https://pdxscholar.library.pdx.edu/honorstheses

Let us know how access to this document benefits you.

\section{Recommended Citation}

Sample, Mikhaela C., "Facility Location Model for Free Clinics to Address Healthcare Disparities in Portland, OR" (2018). University Honors Theses. Paper 603.

https://doi.org/10.15760/honors.613

This Thesis is brought to you for free and open access. It has been accepted for inclusion in University Honors Theses by an authorized administrator of PDXScholar. Please contact us if we can make this document more accessible: pdxscholar@pdx.edu. 


\title{
Facility Location Model for Free Clinics to Address
}

Healthcare Disparities in Portland, OR

\author{
by \\ Mikhaela C. Sample
}

An undergraduate honors thesis submitted in partial fulfillment of the

\author{
requirements for the degree of \\ Bachelor of Science
}

in

University Honors

and

Civil Engineering

Thesis Advisor

Dr. Avinash Unnikrishnan

Portland State University

2018 


\begin{abstract}
Americans are consistently spending more time and money on their healthcare. The increase in spending is not consistent across all demographics. Minority and lower-income individuals are often spending the most. The locations of healthcare facilities are a key contributor to this discrepancy. The distance an individual must travel for healthcare leads to their exclusion from accessing that facility if the distance is too great. Engineers work to remedy this disparity in access using facility location models. The work presented herein uses one such model to address healthcare disparities in Portland, Oregon. The formulation is a maximal covering location model that uses mixed integer programing parameters. The objective is to maximize medical coverage for the targeted demographics through the strategic opening of free of cost satellite medical facilities.
\end{abstract}

\title{
Keywords
}

Facility Location Model, Healthcare Disparities, \& Exclusion by Distance

\section{Acknowledgements}

I want to thank my advisor, Professor Unnikrishnan, who gave me this opportunity to translate my work as an engineer into work in healthcare. I am also thankful for all his time and expertise given throughout the course of this project, without which this work would not have been possible.

I also want to thank my fellow student and data analyzing pro, Darshan Chauhan, for all his time and work put into the project, both before and after my taking it on. His openness to help and sharing of his wisdom is the only way this work was completed in a timely manner.

I want to extend a thank you to Dr. Clifton for all her insights into the world of healthcare and the ways in which transportation plays a part. Additional thanks to Michael Goins for his GIS work during the eleventh hour.

I want to thank Mike Barry and Parry Sample for opening my eyes to the world of healthcare disparities in Portland, Oregon and their advice on how to address them through the lens of nondiscriminatory policies and equitable access.

Lastly, thanks to Prof. Starry and the Honors college for the opportunity to pursue my interests and further my academic career. 


\section{Abbreviations}

AFAB

AMAB

ASCE

CDC

ENDO

$\mathrm{GHG}$

$\mathrm{HCF}$

MCLP

MIP

OB/GYN

SIDS

SMF

WHO
Assigned Female at Birth

Assigned Male at Birth

American Society of Civil Engineers

Center for Disease Control

Endocrinologist

Greenhouse Gas

Healthcare Facility

Maximal Covering Location Problem

Mixed Integer Programing

Obstetrician / Gynecologist

Sudden Infant Death Syndrome

Satellite Medical Facility

World Health Organization 


\section{Table of Contents}

Abstract

Keywords

Acknowledgements

Abbreviations

List of Figures

1. Motivation

2. Background

3. Purpose

4. Literature Review

4.1 Mathematical

4.1.1 Mathematical Background

4.1.2 Related Works

4.2 Medical

4.2.1 Postpartum Care

4.2.2 Diabetes Treatment

5. Model

Synopsis

6. Obtaining the Parameters 10

$\begin{array}{ll}6.1 \text { Neighborhoods } & 10\end{array}$

6.2 Possible Facility Locations 12

6.3 Medical Physicians 12

6.5 Services

6.4 Demographics

6.6 Distances 14

$\begin{array}{ll}6.7 \text { Radii of Coverage } & 15\end{array}$

7. Results 16

8. Implications 20

8.1 Run Times 20

8.2 Ways to Increase Coverage $\quad 21$

$\begin{array}{lll}8.3 & \text { Facilities to Open } & 21\end{array}$ 
9. Conclusion 23

Future Research $\quad 23$

$\begin{array}{ll}\text { References } & 24\end{array}$

Appendix A: Community center coordinates counts of opening across all trials 27

Appendix B: Python Code and Script 28

\section{List of Figures}

Figure 1: discrete location problem overview courtesy of "A survey of healthcare facility location" 4

Figure 2: Infant mortality rates by race and ethnicity (2015) courtesy of the CDC 5

Figure 3: Maternal mortality on the rise courtesy of the Lancet 6

Figure 4: Percentage of US population diagnosed with diabetes by race and ethnicity courtesy of the National Diabetes Statistics Report, 2017

Figure 5: Map of census tracts and Portland neighborhoods courtesy of Chauhan 11

Figure 6: Travel distance by transit in Portland, OR courtesy of Mapnificent 16

Figure 7: Run Times $\quad 17$

Figure 8: Percent of Coverage 17

Figure 9: Facility locations by counts across all trials 18

Figure 11: Coverage by number of doctors at fixed radii 19

Figure 12: Coverage by number of open facilities $\quad 20$

Figure 13: Top facilities to open $\quad 22$ 


\section{Motivation}

Professional organization and the members that comprise them are often bound to a code of ethics. For example, medical practitioners are bound to the Oath of Hippocrates that protects patients' rights and privacy while also calling physicians to treat patients humanely. Engineers are similarly bound to act ethically. The American Society of Civil Engineers (ASCE) Code of Ethics Canon 1 states that:

"Engineers shall hold paramount the safety, health, and welfare of the public and shall strive to comply with the principles of sustainable development in the performance of their professional duties." [1]

Within the transportation branch of civil engineering, this canon is commonly upheld through data analysis and modeling. Engineers use this analysis to evaluate safety performance measures. For example, transportation engineers analyze crash data to improve the safety of roadway networks. They also work to create models for determining optimal facility locations for a variety of services. When specifically addressing public safety and health, engineers work to determine the optimal locations to open hospitals, clinics, and ambulatory services. These decisions are based upon constraints, i.e. budget, personnel available, and services offered. The misallocation of services and facilities has severe adverse effects on public health. For example, the distance an individual has to travel from their residence to medical facilities is a critical component of facing exclusion from that facility. This type of exclusion is part of a larger issue of access [2]. Transportation engineers cannot monitor or control an individual's exclusion from a facility once the individual arrives at said facility; however, the engineer's analysis is critical in reducing the exclusion they experience by distance.

Distance is just one factor in the multi-layered issue of access and who is granted it. Distance effects all individuals; however, distance to medical facilities is often greater for the lower socioeconomic classes [3]. The greater distance travelled by these groups is reflected in the opportunity cost associated with receiving basic medical care in the United States. In this example, opportunity cost is equal to the time spent by an individual seeking care times the wage they could have earned working for the same period of time. Research from the National Travel Survey (NTS) shows that individuals identifying as black or Hispanic spent approximately $25 \%$ more time per medical visit than those that identified as white $[3,4]$. The study shows that the average face-to-face time with physicians was consistent across all demographics; consequently, the discrepancy in time spent for a medical visit was the result of increased travel and wait times $[3,4]$.

A solution to reducing travel and wait times is to open more facilities; however, real world constraints such as budget and personnel available limit the number of facilities, and thus the 
capacity, to some fixed value. The problem having a fixed nature of both the capacity and set of locations lends itself to engineers to model. An engineer can use a discrete facility location model to optimize the locations of facilities to open in order to maximize coverage and reduce travel distance for targeted demographics. The model can include additional inputs that optimize demographic demand for services and needs by assigning specific physicians and services to the open facilities. For example, a facility in an area with predominantly Spanish speakers can have bilingual physicians assigned.

\section{Background}

The work presented in thesis builds upon an earlier model to locate free clinics in Portland, Oregon [5]. The model was designed with the ASCE Code of Ethics Canon 1 in mind. In addition to specifically addressing the tenant of upholding public safety and health by opening medical facilities, the model addresses both the burden of cost and socio-economic exclusion affiliated with medical services. The model addresses these issues by categorizing the facilities as free Satellite Medical Facilities (SMFs). A SMF operates under a larger institution but located further away from the main medical facility [6]. The SMF can have resources supplied by the larger institution and be strategically located to reduce travel distances. The strategic placing of SMFs is a key component in reducing exclusion by distance.

The free nature of the SMFs addresses another facet of exclusion: the rising cost of healthcare in the United States which creates a barrier between patients and treatments. In 2015, the rate of spending on healthcare outpaced both inflation and wage growth [7]. A trend that is likely to continue and is echoed by the amount of time Americans spend on healthcare. The average American spends 121 minutes per physician visit [3, 4]. In 2010, this amounted to 1.1 billion hours spent seeking healthcare with an estimated opportunity cost totaling \$52 billion [3]. This increase in time and money spent on healthcare disproportionately affects older and minority populations and health insurance coverage is not keeping pace. According to the Oregon Health Insurance Survey, an estimated 107,000 individuals in Portland are classified as "poor" with $12.4 \%$ of Multnomah County residents listed as having no health insurance [8]. The free of cost services offered at the SMFs further access for disadvantaged groups through reducing the barrier of cost.

\section{Purpose}

The purpose of this work is to use an optimization model to determine a set of satellite medical facilities (SMFs) that reduces the exclusion by distance, from medical care, experienced by lower income and minority populations in Portland, Oregon. The work aims to address this problem through the lens of ethical professionalism as outlined by the ASCE Code of Ethics. In keeping with that code, the model created upholds the tenant of holding public safety paramount and the call for sustainable development. The thesis aims to answer the question: 
"What SMFs, from a given set, should be opened and how should they be staffed to increase medical coverage and reduce travel distances for lower income and minority populations in Portland, Oregon?"

\section{Literature Review}

The formulation of the model requires two types of literature reviews. The first is the review of similar models to create the mathematical component. A background on the development of facility location models is included for clarity. The second review is of the medical services focused upon: postpartum care and diabetes treatments.

\subsection{Mathematical}

\subsubsection{Mathematical Background}

The first facility location model was designed by Alfred Weber in 1909 [9]. He designed a warehouse location problem to minimize travel distances between warehouses and consumers. Since that time, research into the field of facility location modeling has broadened into almost every field of study that involves spatially distributed demands; consequently, there exists a large body of literature related to facility location models. To focus the scope, the literature review looks at models specifically addressing healthcare facility (HCF) problems. In the taxonomy provided by Revelle et al. [10] classifying the location problems based upon the space they occupy, the majority of HCF models are discrete location problems.

The discrete location model assumes discrete sets of both demands and locations. This is why it is favored for HCF models as both demands and locations can be fixed within the given study area. The HCF models are further classified and separated from other types of facility location models by the work of Daskin and Dean. They classified HCF models into three categories: accessibility, adaptability, and availability [11]. The accessibility type model goal is to maximize coverage while reducing travel distances. It is the common model type encountered in HCF literature as it is the more standard form of a discrete facility location problem.

The discrete location problem has several types (see figure 1). The accessibility category fits within the framework of maximal covering location problems (MCLP). The MCLP determines the locations of open facilities $(p)$ from a predetermined set of possible locations with a fixed radius of travel distance to maximize the coverage of the facilities. Common MCLP objective functions are to maximize coverage, minimize travel distances or costs or some combination thereof. The intention of this model is to maximize coverage. 


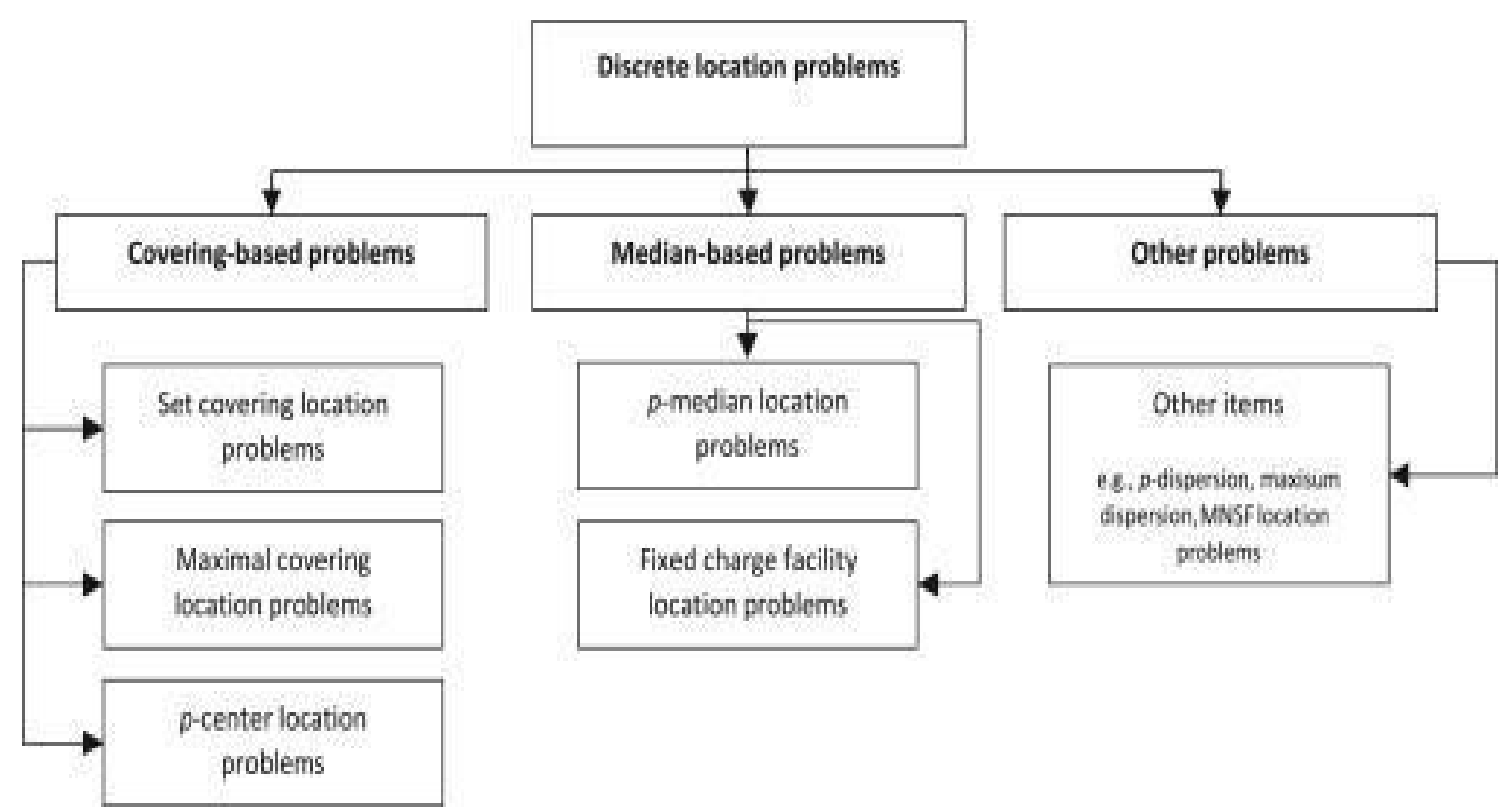

Figure 1: discrete location problem overview courtesy of "A survey of healthcare facility location"

\subsubsection{Related Works}

The objective function of the model is to increase medical coverage for targeted demographics. To that end, a MCLP is the base model adopted. Traditional MCLPs are uncapacitated in nature; however, in reality medical facilities have a fixed capacity. The inclusion of the capacity of the medical facilities alters the basic formulation. Reality imposes more constraints than just fixed capacity; e.g. fixed number of facilities, fixed number of medical personnel, and inability of medical personnel to treat patients with symptoms outside their scope of expertise. There exists a large body of research to address these constraints and create more realistic models. For example, Syam and Cote, working with the Department of Veteran Affairs, use a locationallocation model to improve specialized healthcare services for patients suffering from strokes and other traumatic brain injuries [12]. Their model includes 20 possible facilities, 50 admission districts, fixed capacity of up to 5 open facilities with three services provided for varying levels of severity. The objective function for the model is solved in approximately 300 seconds. Teo adapts the formulation to address ethnicity prejudices in medical coverage in Bamyan Province, Afghanistan [13]. The model takes into account that individuals of certain ethnicities are not likely to attend facilities staffed by individuals of another ethnicity. These individuals are willing to travel farther distances to reach facilities staffed by the same ethnicity; however, this comes at an increased cost. Guo et al. created a model to address China's inequity in access to its healthcare facilities [14]. The model's objective function was to minimize both fixed and variable costs. The authors used a hybrid of panel data analysis and augmented data envelopment analysis to scale resources and determine efficiency of the allocation of community health centers in Jiangsu Province. In Malaysia, Shariff et al. used a capacitated MCLP in conjunction with a genetic algorithm to determine the medical coverage of the existing facilities within a 
radius dictated by the Malaysian government [15]. Baray and Cliquet looked specifically at maternity clinics in France and incorporated a three-tiered hierarchical model to optimize coverage [16]. The first tier was MCLP and the remaining tiers were p-median. Their work also included a probability factor to predict congestion at the clinic and restrict access to the facility when overly congested. Another three-tier example, Galvao et al. used the tiers and load balancing model to minimize travel distances for perinatal clinics in Rio De Janerio, Brazil [17]. The work also includes a heuristic of Lagrangian Relaxation to solve the objective function. These related works have the common objective functions of MCLP. The work presented herein focuses on maximizing medical coverage with fixed travel of distance (radii of coverage) and capacitated number of doctors and facilities.

\subsection{Medical}

\subsubsection{Postpartum Care}

The Center for Disease Control (CDC) in America tracks infant mortality rates. Infants being persons under one year of age [18]. The top five causes of death for infants in 2015 were: birth defects, low birth weight, sudden infant death syndrome (SIDS), maternal pregnancy complications, and injuries [18]. Their data shows that infant mortality is not uniform across race and ethnicity (see figure 2). For example, non-Hispanic black individuals have over twice the infant mortality rate of non-Hispanic white individuals (11.3 deaths as compared to 4.9 deaths per 1,000 live births, respectively). Additionally, the cause of death for infants of maternal pregnancy complications sheds light on another individual in danger: the mothers.

\section{Infant Mortality Rates by Race and Ethnicity, 2015}

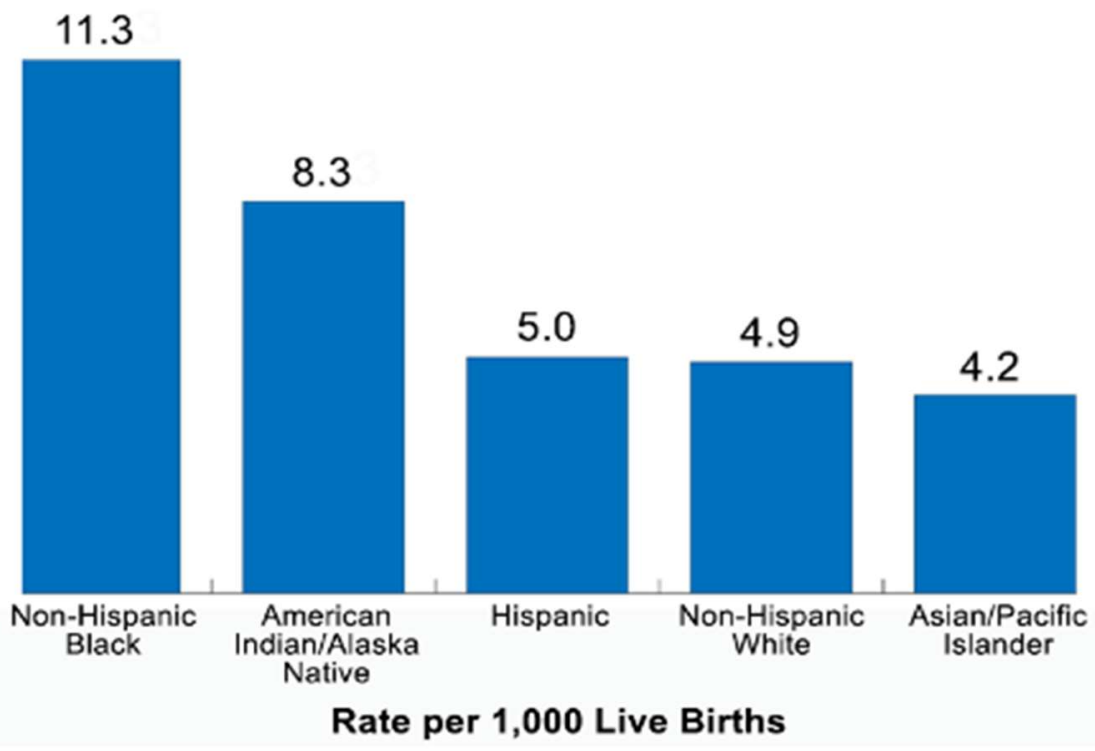

Figure 2: Infant mortality rates by race and ethnicity (2015) courtesy of the CDC 
Maternal mortality is on the rise in American while it is declining in other developed nations (see figure 3). The CDC Foundation says that nearly $60 \%$ of these deaths are preventable [19]. Similarly to infant mortality, maternal mortality is not uniform across race and ethnicity. For example, black women have a 3 to 4 times higher risk for pregnancy related deaths as compared to white women [20]. The CDC defines a pregnancy-related death as one occurring within one year of the end of the pregnancy occurring because of: "pregnancy complication, a chain of events initiated by pregnancy, or the aggravation of an unrelated condition by the physiologic effects of pregnancy" [19]. A recommendation for women to prevent pregnancy related deaths is continuous monitoring by medical providers [19]. The health of the mother is imperative for the health of the infant as well. The World Health Organization (WHO) states that most critical phase for both mother and infant is during the postnatal period which is the first three months after birth [21]. They recommend that mother and infant visit a medical provider at least three times during this period [21]. A physician specializing as an obstetrician or gynecologist $(\mathrm{OB} / \mathrm{GYN})$ is capable of treating women and infants in the postpartum period.

\section{Maternal Mortality Is Rising in the U.S. As It Declines Elsewhere Deaths per 100,000 live births}

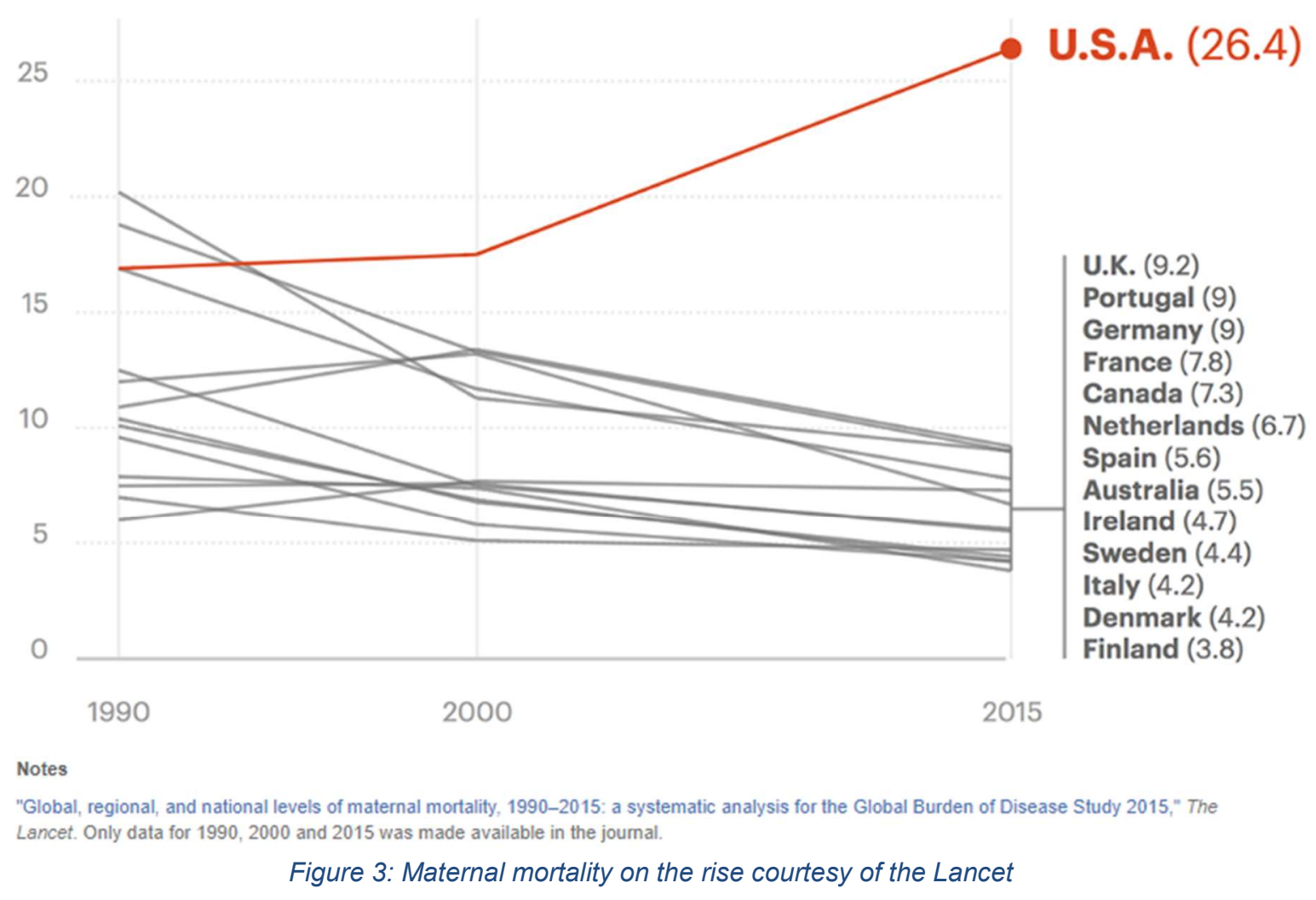




\subsubsection{Diabetes Treatment}

Diabetes is the 7th leading cause of death in America [22, 23]. Nearly 9.4\% of the U.S. population has diabetes of either type 1 or type 2 [22]. Diabetes is more prevalent among senior populations with $25.2 \%$ of Americans aged 65 and older having diabetes [22]. Diabetes is also more prevalent among certain races and demographics. For examples, 12.7\% of non-Hispanic blacks are diagnosed with diabetes compared to 7.4\% of non-Hispanic whites (see figure 4). American Indians and Alaskan Natives are double the rate of non-Hispanic whites with 15.1\% rate of diagnosis (see figure 4). These are just the rates of diagnosis. Many individuals living with diabetes are undiagnosed and it may be underreported as a cause of death [22]. The United States has average deaths of 19.3 for white individuals and 36.8 for black individuals per 100,000 for [23]. Oregon ranks worse than average with deaths of 23.9 for white individuals and 40.8 for black individuals per 100,000 [23]. Both types of diabetes are treatable when regulated. This regulation is under the supervision of a specialized physician such as an endocrinologist (ENDO). For individuals diagnosed with diabetes, patients are recommended to visit their medical providers once every three months [22].

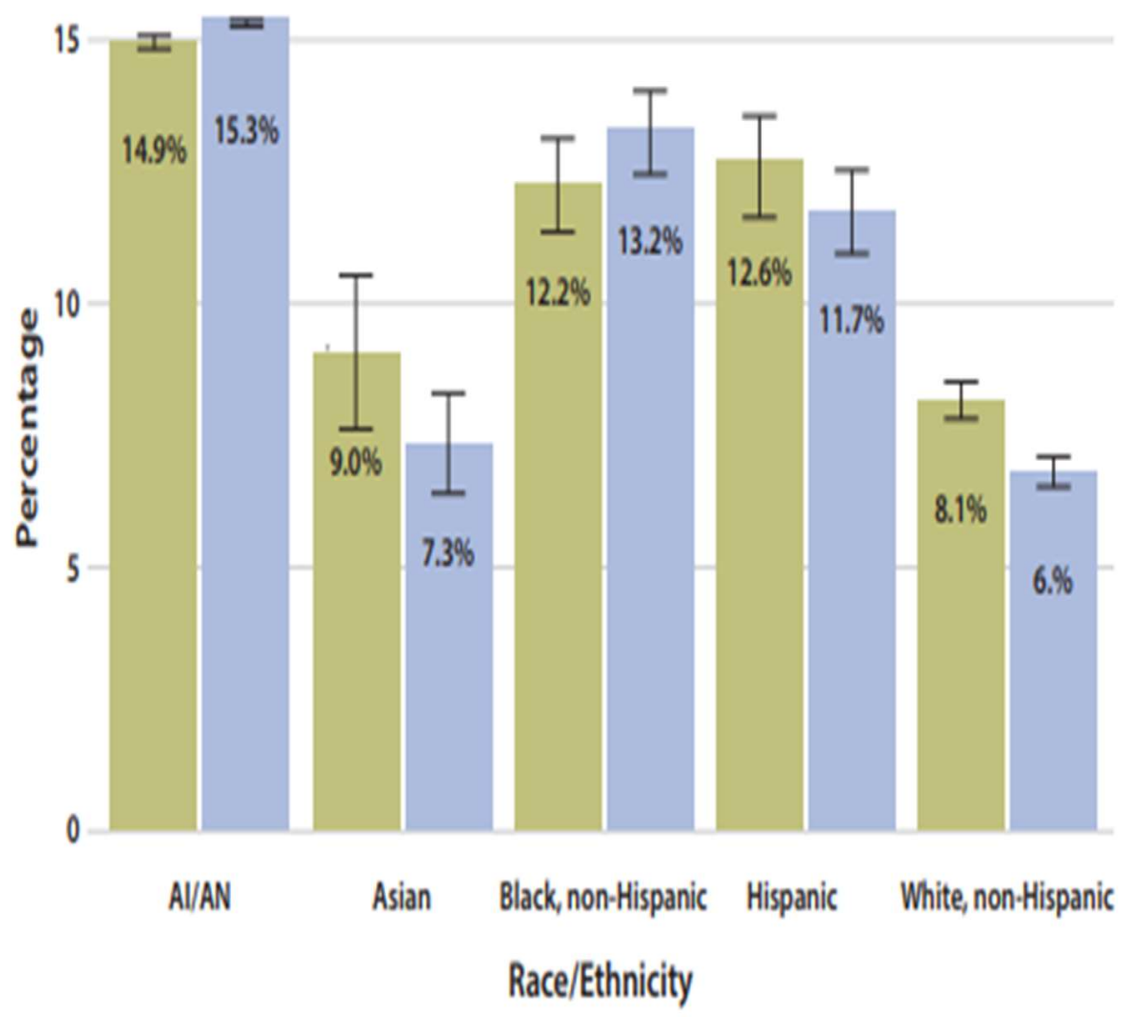

$\mathrm{A} / \mathrm{AN}=$ American Indian Alaska Native.

Note: Error bars represent upper and lower bounds of the $95 \%$ confidence interval.

Data source: 2013-2015

National Health Interview

Survey, except American

Indian/Alaska Native data, which are from the 2015

Indian Health Service

Men National Data Warehouse.

Women

Figure 4: Percentage of US population diagnosed with diabetes by race and ethnicity courtesy of the National Diabetes Statistics Report, 2017 


\section{Model}

Sets

$I \quad$ : Set of all neighbourhoods/demand points. (Cardinality $=95$ )

$J \quad$ : Set of all potential facility locations. (Cardinality $=31$ )

$N$ : Set of all doctors/personnel. (Cardinality $=50$ )

$S \quad$ : Set of all services. (Cardinality $=3$ )

$D$ : Set of all demographics. (Cardinality $=6$ )

Indices

$$
\begin{aligned}
& i \in I \\
& j \in J \\
& n \in N \\
& s \in S \\
& d \in D
\end{aligned}
$$

Input Parameters

$p \quad$ : maximum number of facilities that must be opened. $\{p \leq|J|\}$

$h_{i d s} \quad$ : Demand for service ' $s \in S$ ' by demographic ' $d \in D$ ' in neighbourhood ' $i \in I$ '.

$V_{n d s}:$ Capacity of $n^{\text {th }}$ doctor/personnel who can handle a service ' $s \in S$ ' for a demographic ' $d \in D$ ' if s/he spends $100 \%$ time on it.

$R_{j} \quad$ : Radius of coverage of $j^{\text {th }}$ facility location.

$M_{i}=\left\{j \mid d(i, j) \leq R_{j}\right\} \quad \forall i \in I, j \in J$

$M_{j}=\left\{i \mid d(i, j) \leq R_{j}\right\} \quad \forall i \in I, j \in J$

Decision Variables

$Y_{j}: \begin{cases}1 & \text { if facility is opened at ' } j \\ 0 & \text { otherwise }\end{cases}$

$X_{j i d s}$ : Fraction of demand of a service ' $s \in S$ ' of a demographic ' $d \in D$ ' in a neighbourhood ' $i \in I$ ' satisfied at facility location ' $j \in J$ '.

$U_{i d s} \quad$ : Fraction of unmet demand of a service ' $s \in S$ ' of a demographic ' $d \in D$ ' in a neighbourhood ' $i \in I$ '.

$B_{j n}: \begin{cases}1 & \text { if doctor/personnel ' } n \text { ' is stationed at facility location ' } j \text { '. } \\ 0 & \text { otherwise }\end{cases}$

$W_{\text {jnds }}$ : Fraction of time spent by $n^{\text {th }}$ doctor/personnel on service ' $s$ ' of demographic ' $d$ ' at facility location ' $j$ '. 
Objective Function

$$
\text { Minimize } \sum_{i \in I} \sum_{d \in D} \sum_{s \in S} h_{i d s} \cdot U_{i d s}
$$

\section{Constraints}

$$
\begin{gathered}
\sum_{j \in M_{i}} X_{j i d s}+U_{i d s}=1 \quad \forall i \in I, d \in D, s \in S \\
\sum_{i \in M_{i}} X_{j i d s} \cdot h_{i d s}-\sum_{n \in N} W_{j n d s} . V_{n d s} \leq 10 \quad \forall j \in J, d \in D, s \in S \\
\sum_{j \in D} Y_{j}=P \\
\sum_{s \in S} W_{j n d s}=B_{j n} \quad \forall j, n \\
\sum_{j \in J} B_{j n} \leq 1 \quad \forall j, n, d, s \\
W_{j n d s} \leq B_{j n} \quad \forall j, n \\
B_{j n} \leq Y_{j} \\
Y_{j}, B_{j n} \in\{0,1\} \\
\forall U_{i d s}, W_{j n d s} \in[0,1]
\end{gathered}
$$

\section{Synopsis}

The objective function (eq. 5.1) is to minimize the total unmet demand across all neighborhoods (i) for all demographics (d) for all services (s). The constraints apply realism to the formulation. The first two constraints are standard for most facility location models. The first constraint (eq. 
5.2) ensures that the sum of met and unmet demand totals $100 \%$ for each service of each demographic in each neighborhood. The next constraint (eq. 5.3) ensures that the demand for each service at a facility is less than or equal to the capacity of the doctors assigned to that facility. The following constraints are specialized for this model. Equation 6.4 ensures that all the facilities (p) are opened. Equations 5.5 and 5.6 ensures that doctors are assigned to the demographics and services they have the capacity to meet. Equations 6, 7, and 8 are nominal conditions. Equation 5.9 ensures that no doctor serves at more than one facility. The coverage for this formulation is defined as the percentage of the demand for medical care received by the targeted demographics

The formulation data set contains 84,201 variables and 33,269 constraints. The problem is a Mixed Integer Programing (MIP) problem with binary constraints as the integer variables. The program is coded in Python and solved using Gurobi Optimizer through Spyder. The hardware used for running the code is Dell Optiplex 7010 CPU with 8 gigabytes of RAM and an Intel i73770 processor.

\section{Obtaining the Parameters}

\subsection{Neighborhoods}

The 2015 US Census provided the data for each neighborhood. The census data collection is organized, from smallest to largest, as follows:

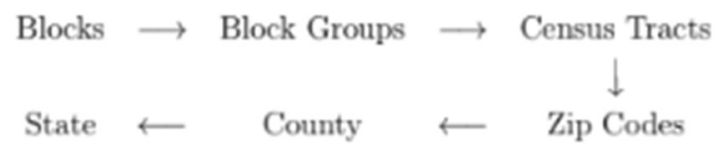

The block contains the highest resolution (smallest area) but the least amount of information in terms of categories available. Conversely, the state contains the lowest resolution and the greatest amount of information. The census tract and zip codes are a balance between high and low resolutions and amount of information available. Portland contains 144 census tracts and 32 zip codes. The 32 zip codes are too broad an area of coverage and does not provide enough data points for the resolution preferred by the engineer. Therefore, the census tracts serve as the basis for the neighborhoods. The census tract contains data regarding population by sex, race / ethnicity, household information, poverty levels, and fertility rates. However just as 32 was too low a sample size, 144 is too large. To narrow the focus, the census tract information was qualitatively reassigned to 95 Portland neighborhoods. These neighborhoods have no legal boundaries; however, they are recognizable to Portland residents and are more familiar than the census tracts. They include areas such as Alameda and Goose Hollow. A map of the Portland census tracts overlain with the qualitative neighborhoods is shown (see figure 5) each 
neighborhood is condensed to a single coordinate with a latitude and longitude. The coordinate serves as an approximation for the center of the neighborhood and functions as a single node.

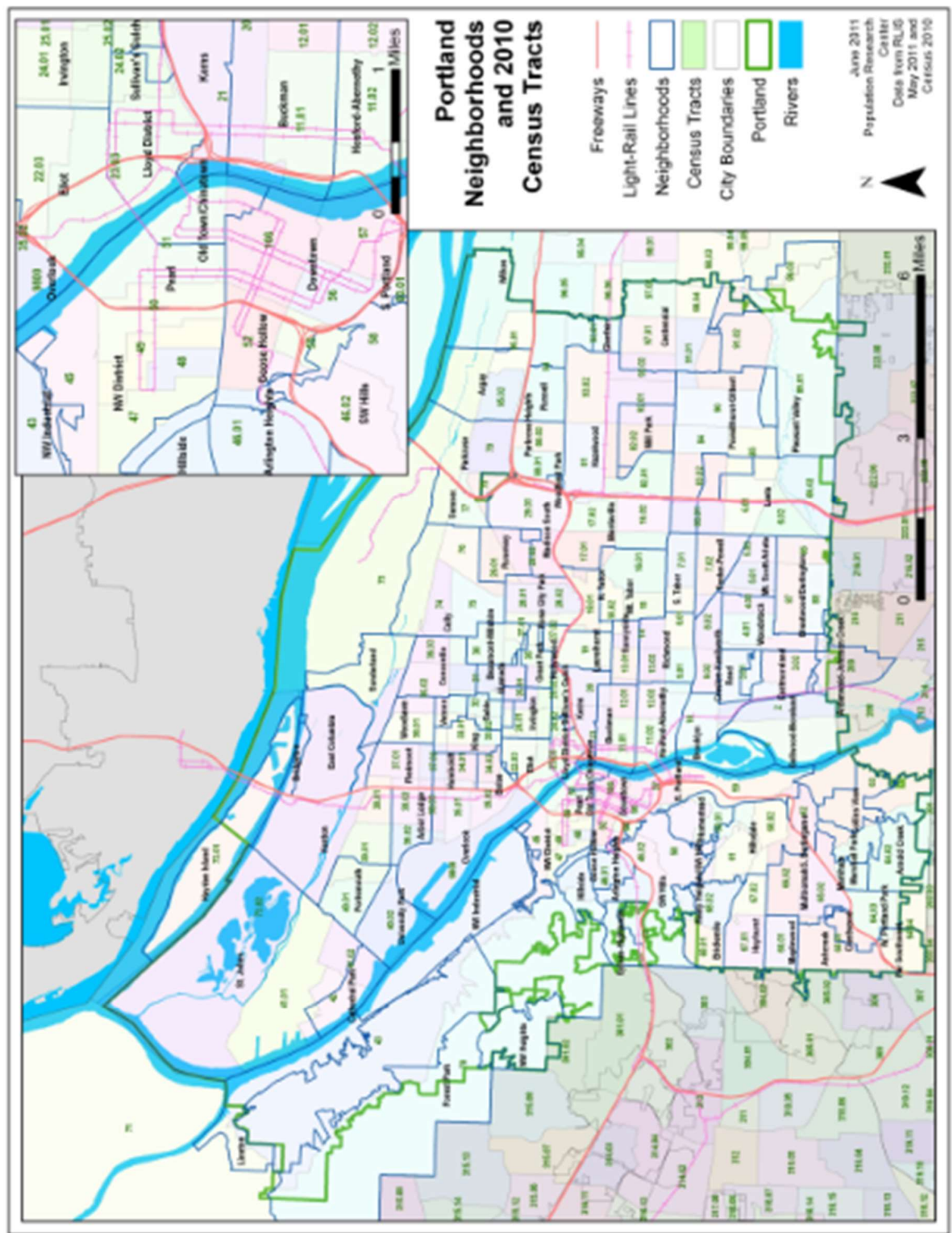

Figure 5: Map of census tracts and Portland neighborhoods courtesy of Chauhan 


\subsection{Possible Facility Locations}

Construction related activities are a significant contributor to global greenhouse gas (GHG) emissions. To minimize GHG emissions and adhere to the ASCE Code of Ethics Canon 1's call to strive for sustainable solutions, only existing structures were selected as possible SMF locations. As the intention of the model is to create better access for communities and aims to improve local resources, community centers in Portland were chosen as the possible SMF locations. Community centers provide the adequate space required to host clinics and are recognized as accessible and low barrier establishments within the communities they serve. A total of 31 community centers in Portland were selected as possible locations. To fit within the hours of operation for the community centers, the SMFs are operational 5 days-a-week with 10 working-hours-a-day. Due to budget and feasibility constraints, they are operational 250 days a year. This is slightly less than the 261 working days a year recognized by most contract work. Similar to the neighborhoods, the community centers are idealized to a single coordinate with latitude and longitude that serves as a single node.

\subsection{Medical Physicians}

The doctors are comprised of two specialties: Endocrinologists (ENDO) and Obstetricians / Gynecologists $(\mathrm{OB} / \mathrm{GYN})$. Based on the amount census tract information for fertility rates, it was determined that $10 \%$ of the physicians be OB/GYN. The remaining $90 \%$ are ENDO. Based on the number of Spanish speakers in Portland that comprise the target demographics, i.e. those of Hispanic origin, it was determined that $20 \%$ of the medical professionals be fluent in Spanish. The capacity of the remaining $80 \%$ of physicians is 0 to treat Spanish speaking patients. The capacity of each doctor is based upon a face-to-face time of 20 minutes per patient [3, 4]. Based upon the Medicare/Medicaid fee coding system of relative value unit (RFU), an intermediate office visit includes 5 minutes of prep for each patient and 10 minutes of post-visit work for a total of 15 minutes [24]. An additional 5 minutes is included per visit to account for walking and break times. Therefore, the capacity of each doctor specialty to perform each service for each type of demographic (granted their capacity to do so is not 0 ) is a random integer between 3300 and 4100 patients. This is the capacity +-400 for seeing patients 5 hours of the 10 -hour working day 250 days a year (the operational clinic hours). The remaining 5 hours of the working day is allotted for prepping for each visit, filing paperwork, other administrative tasks, and breaks as indicated by the RFU time allotment.

With this capacity per doctor, a total of 115 doctors is required to achieve $100 \%$ coverage of the demand. As the clinics operate on a minimal budget, 115 doctors are too large a number to staff at a given time. A more realistic number of doctors, without knowing the budgets of the clinics, is 50 . This value was determined to be the required number of doctors to reach $100 \%$ coverage if the clinics operated 365 days a year. The 50 doctors were the only number of physicians used in the earlier work [5]. Due to an oversight in the earlier work, the doctors were not limited to 
serving at only SMF at any given time. A correction to the code was included in this model to constrain each doctor to only work at one SMF at a time. Based upon the inclusion of this constraint, the results from the earlier work and this work are incompatible. To provide a comparison within this model only, the model was run with the 50 doctors and again with 40 doctors.

List of Assumptions:

- Both ENDO and OB/GYN doctors can serve as primary care physicians and perform routine check-up procedures that do not require a specialty.

- The capacity of ENDO doctors to treat women and infants for postpartum needs is 0 . Similarly, the capacity of OB/GYN doctors to treat patients for diabetes is 0 .

- The number of doctors is only limited by budget and not availability of physicians of each specialty at the percentages listed: 90\% ENDO, 10\% OB/GYN, 20\% Spanish Speaking, and 80\% non-Spanish speaking.

\subsection{Services}

The scope of services provided was limited to three:

1) postpartum care for women and infants (3 visits annually, refer sec 4.2.1),

2) care and treatment for diabetic patients (4 visits annually, refer sec 4.2.2),

3) Primary care for individuals living below the poverty limit ( 2 visits annually, assumed)

The demand for postpartum and primary care was obtained through the American Community Survey (2015) information, at the census tract level, for poverty and fertility data. This data was converted to the neighborhood level to match the model parameters. The demand for postpartum care for individual's assigned male at birth (AMAB) is set to 0 . The demand for diabetic care was obtained from the Multnomah County 2004-20013 database.

\section{List of Assumptions}

- The clinics should have capacity to accommodate two visits annually for each individual living below the poverty line. 


\subsection{Demographics}

Demographic information was compiled by the Population Resource Centre at Portland State University for each neighborhood. The data used was total population, no. of individuals assigned male at birth (AMAB), no. of individuals assigned female at birth (AFAB), and no. of individuals of Hispanic origin. The data focuses upon sex assignments at birth because of the limited information regarding transsexual individuals available at this time; however, it is recognized that these individuals face unique health challenges that future models should address. To best approximate their need, the LGBTQ population is included. This population accounts for 5.4\% of all Portland residents [25, 26, 27]. People of Hispanic origin are focused upon because of the assumed language barrier and information available regarding this population. The assumed language barrier is a conservative constraint to ensure that the individual's medical demand will be met by a bilingual physician. Portland contains numerous other ethnic groups that face socio-economic disparities and language barriers; however, too little information is available at this time to accurately model their demand for services. Consequently, the demographic data is split between AMAB and AFAB individuals of both Hispanic and non-Hispanic origin identifying as either LGBTQ+ or not.

\subsection{Distances}

Each neighborhood and potential SMF are reduced to discrete points of coordinates with both a latitude and a longitude. The discrete points are considered representative of the whole neighborhood or facility. The discrete points can be thought of as a concentration of mass to allow for ease of analysis. The neighborhood coordinates were determined through a qualitative analysis using Google maps. The SMF coordinates were determined using a geographic information system (GIS) software system to extract from the RLIS Discovery Oregon Metro shape file [32]. The distance between each neighborhood and SMF creates a 95 x 31 matrix. The large scale of the matrix made establishing driving distances between each point outside of the scope of this work. For future research, a Python script written for the Google Maps Distance API is recommended to establish not only driving distances but also transit times between each point. To approximate the distances, each origin coordinate (the neighborhood) and each destination coordinate (the SMF) was converted into miles by using the lowest latitude of all the neighborhoods [33]. The conversion slightly overestimates the actual distance and aids in the realism of the problem.

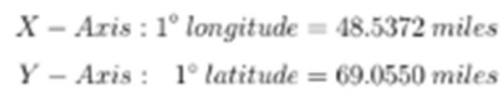

Earlier work used both approximate driving distances (ADD) and Euclidean distances (ED) to determine the distance between the origins and the destinations [5]: 


$$
\begin{gathered}
A D D=X+Y \\
E D=\sqrt{X^{2}+Y^{2}}
\end{gathered}
$$

The solutions from that work considered the ADD as more robust and more realistic than the ED distances; therefore, only distances from ADD were used for this model. Due to the nature of the data file, the distances were input in meters. The distances are integer values and not continuous to ensure that all input parameters are integer values in accordance with the formulation of MCLP (refer sec 4.1.1).

\subsection{Radii of Coverage}

A theoretical maximum was determined to analyze the formulation with the targeted demographics not traveling longer than the average American for a medical visit. The theoretical maximum is 7.4 miles calculated by 18.5 minutes of travel time (half of the 37 total minutes an individual in America travels on average for medical care [3, 4] times the Portland Bureau of Transportations (PBOT) Vision Zero residential speed limit of 20 miles per hour [34]. The residential speed limit is used to determine the theoretical maximum because the nature of the formulation is to keep the demographics local. However, a significant portion of the targeted demographics may not have access to a vehicle [36]. Additionally, driving negatively affects public health through increased GHG emissions and reduced time spent exercising in the form of walking or biking. Additionally, the Internal Revenue Service reports show that the cost per mile of driving is on the rise and the intention is to keep costs minimal $[35,36]$. Furthermore, approximately $24 \%$ of individuals living below the poverty line do not own a vehicle [35]. Therefore, a more conservative maximum is required that does not rely on the use of vehicle.

The more conservative maximum distance was set to 5 miles. This maximum value was qualitatively determined by analyzing a map of distances an individual in Portland can travel via public transit in 19 minutes (see figure 6). The map was generated using the Google Distance API through Mapnificent. All four pins are set to 19 minutes of travel time. As shown, an individual traveling from downtown Portland can travel further in 19 minutes via public transit as compared to an individual in North or Southeast Portland. The maximum distance from downtown Portland that an individual can travel and still be within the neighborhood boundaries established is 5 miles. The minimum distance is 1 mile. This minimum was established using walking distances. The average individual walking speed is $143 \mathrm{~cm} / \mathrm{s}(0.0533 \mathrm{mi} / \mathrm{min})$ [37]. If some individual travels for the 18.5 minutes they would go 0.986 miles. This value is rounded to 1 mile for ease of analysis. This assumes that the individual is both capable of walking that distance both from a personal ability standpoint and that there are no physical barriers along the route that prevent access; e.g. highways or rivers. However, it serves as a realistic minimum distance for individuals to travel whether walking, driving, or taking public transit. 


\section{List of Assumptions:}

- The radius of coverage for each SMF is the same.

- The maximum distance of 5 miles is attainable by public transit in 19 minutes of travel.

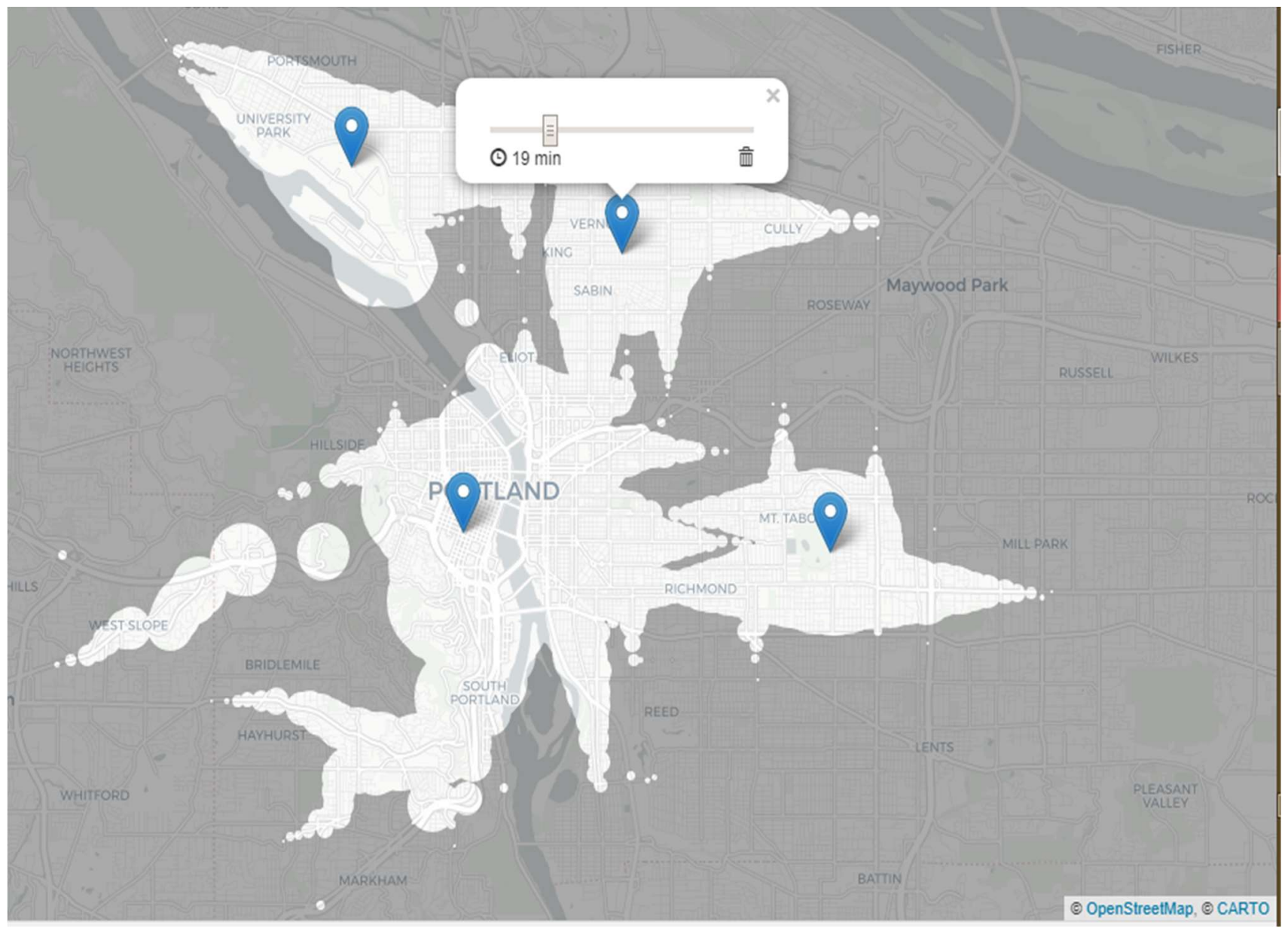

Figure 6: Travel distance by transit in Portland, OR courtesy of Mapnificent

\section{Results}

The model was run 24 times. The number of facilities, radii of coverage, and number of doctors was adjusted for each run. The number of facilities was set to $12,10,8$, or 6 . The radii of coverage (miles) was set to $5,2.5$, or 1 . The number of doctors was either 50 or 40 . The run times ranged from 20 seconds to over 1,600 seconds (26 minutes) (see figure 7). The percent of coverage ranged from $20 \%$ to nearly $50 \%$ (see figure 8 ). Some facilities were never selected to be opened while others were selected over half of the 24 runs (see figure 9 ). The number of facilities had the most significance in percent of coverage when the radii of coverage was 1 mile (see figure 10). Once the radii of coverage increased to 2.5 miles and 5 miles the coverage 
converged between the number of facilities opened. Percent of coverage for 50 doctors was comparable to that of 40 doctors at the same number of facilities and 1mile radii of coverage (see figure 10). Percent of coverage for 50 doctors increased to nearly $10 \%$ more than that of 40 doctors at the same number of open facilities and radii of coverage of 2.5 miles and 5 miles (see figure 11).

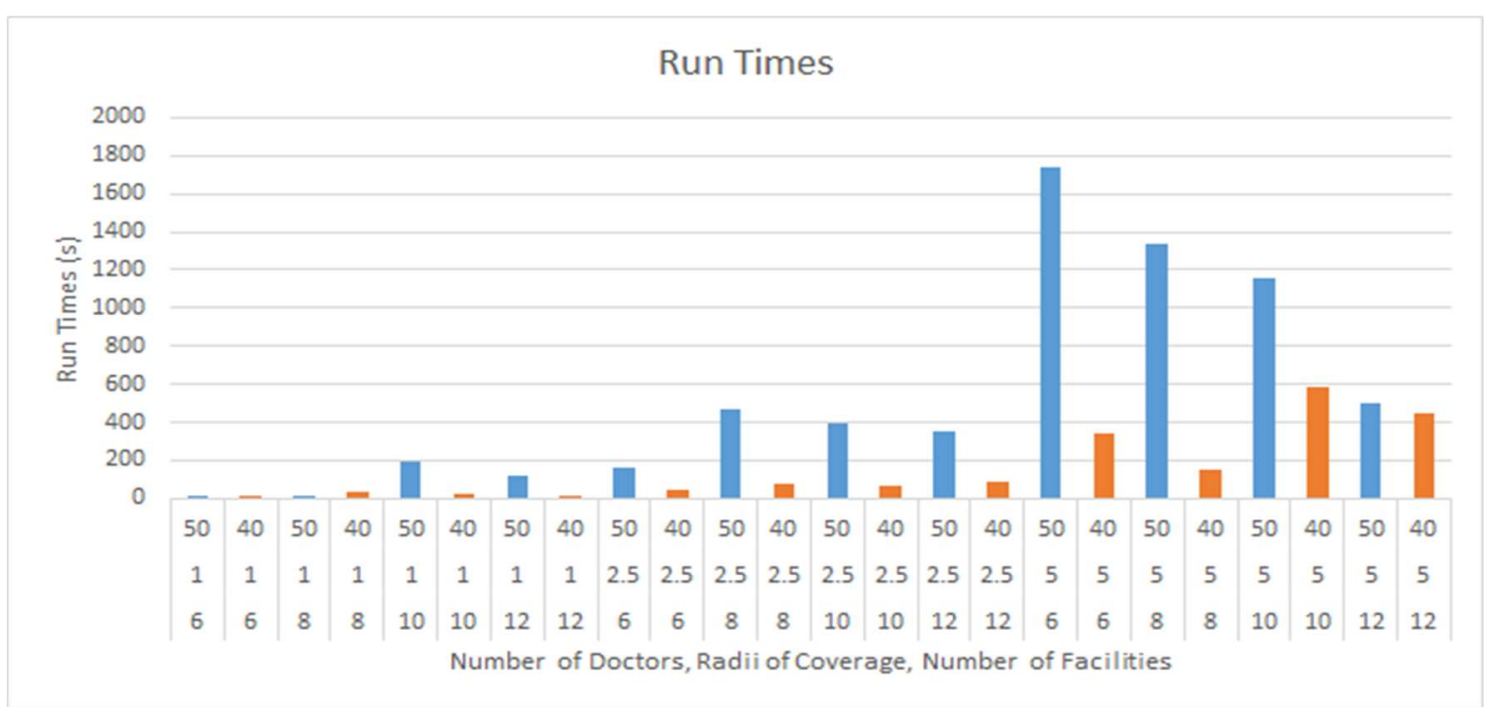

Figure 7: Run Times

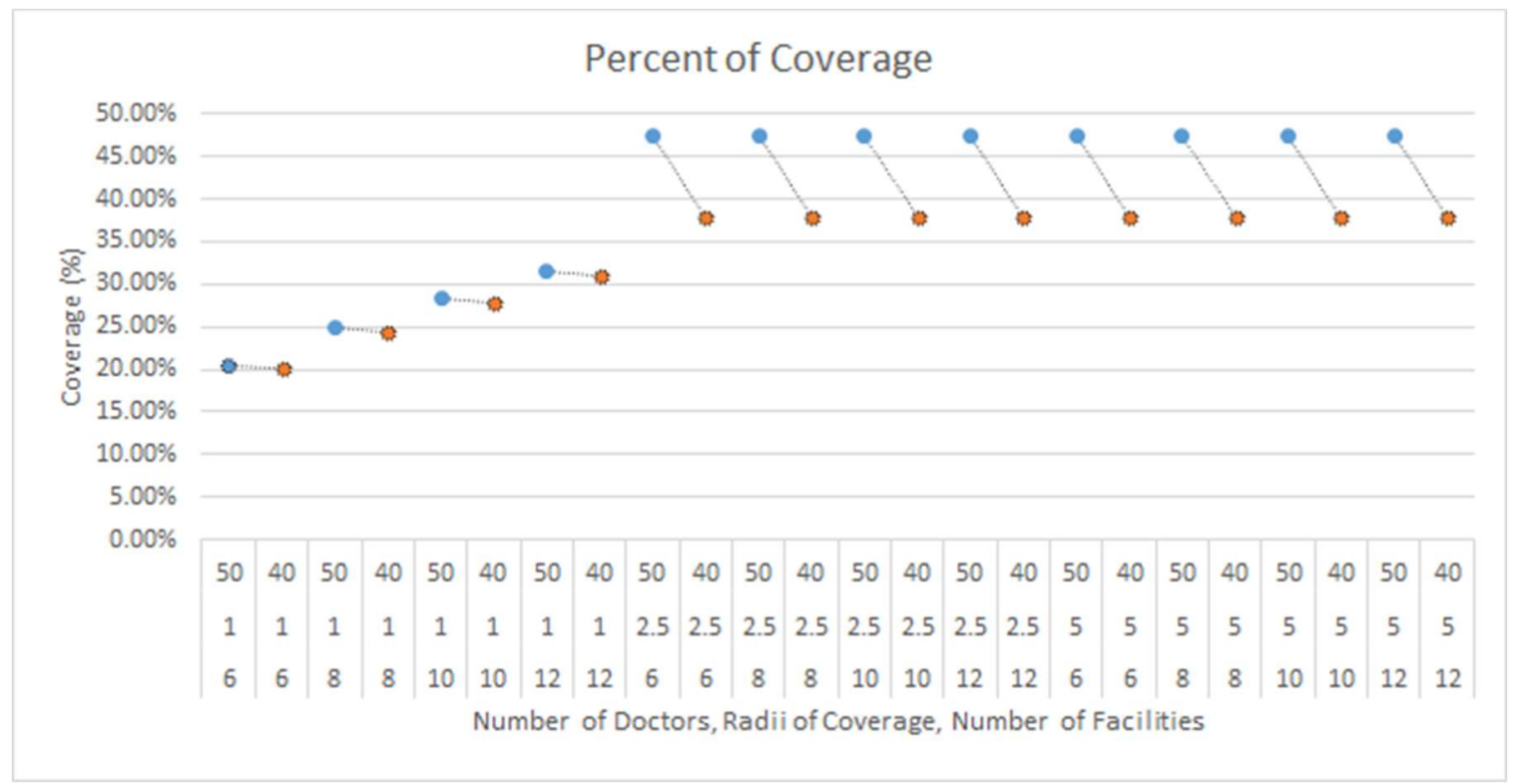

Figure 8: Percent of Coverage 


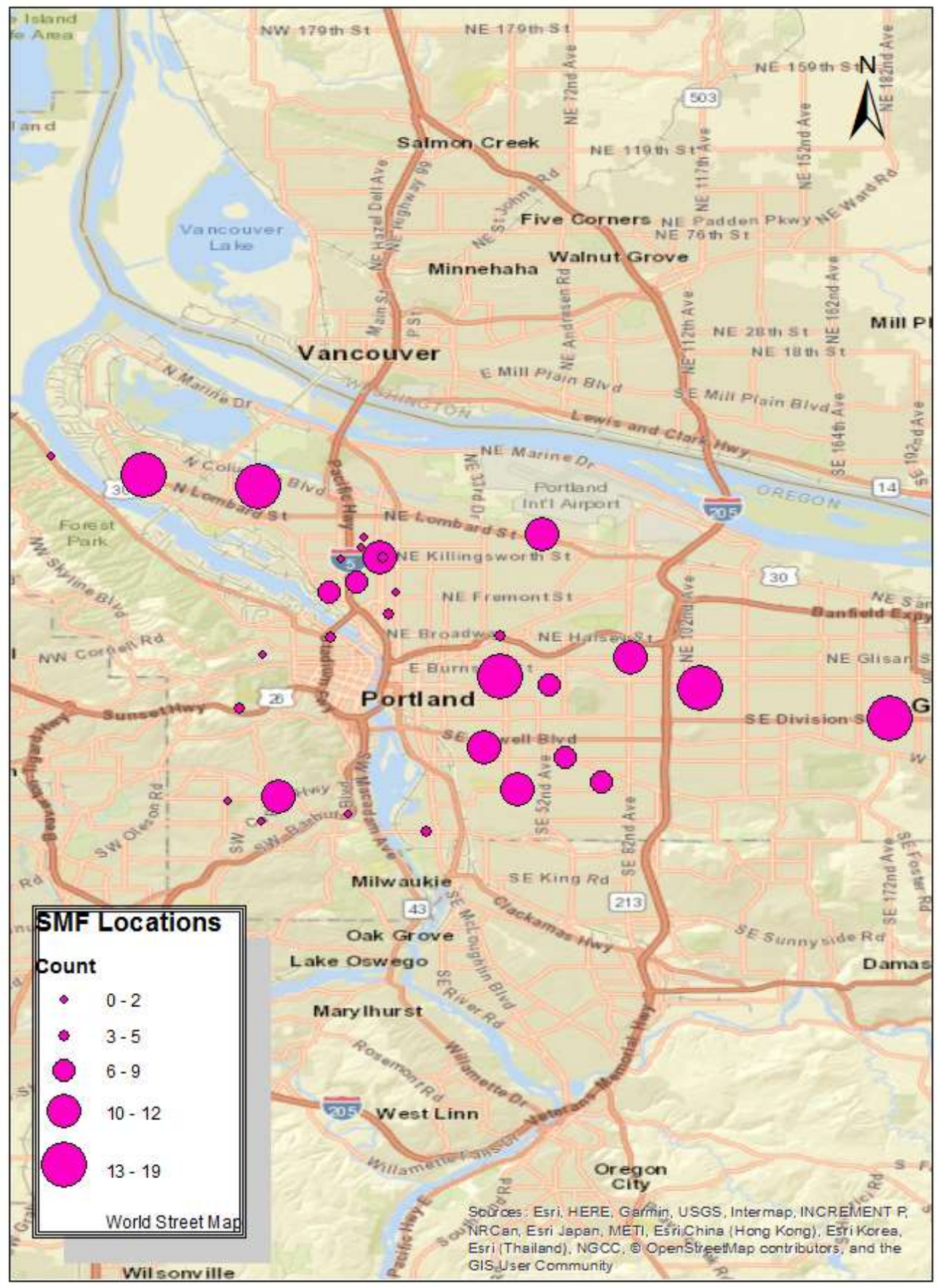

Figure 9: Facility locations by counts across all trials 

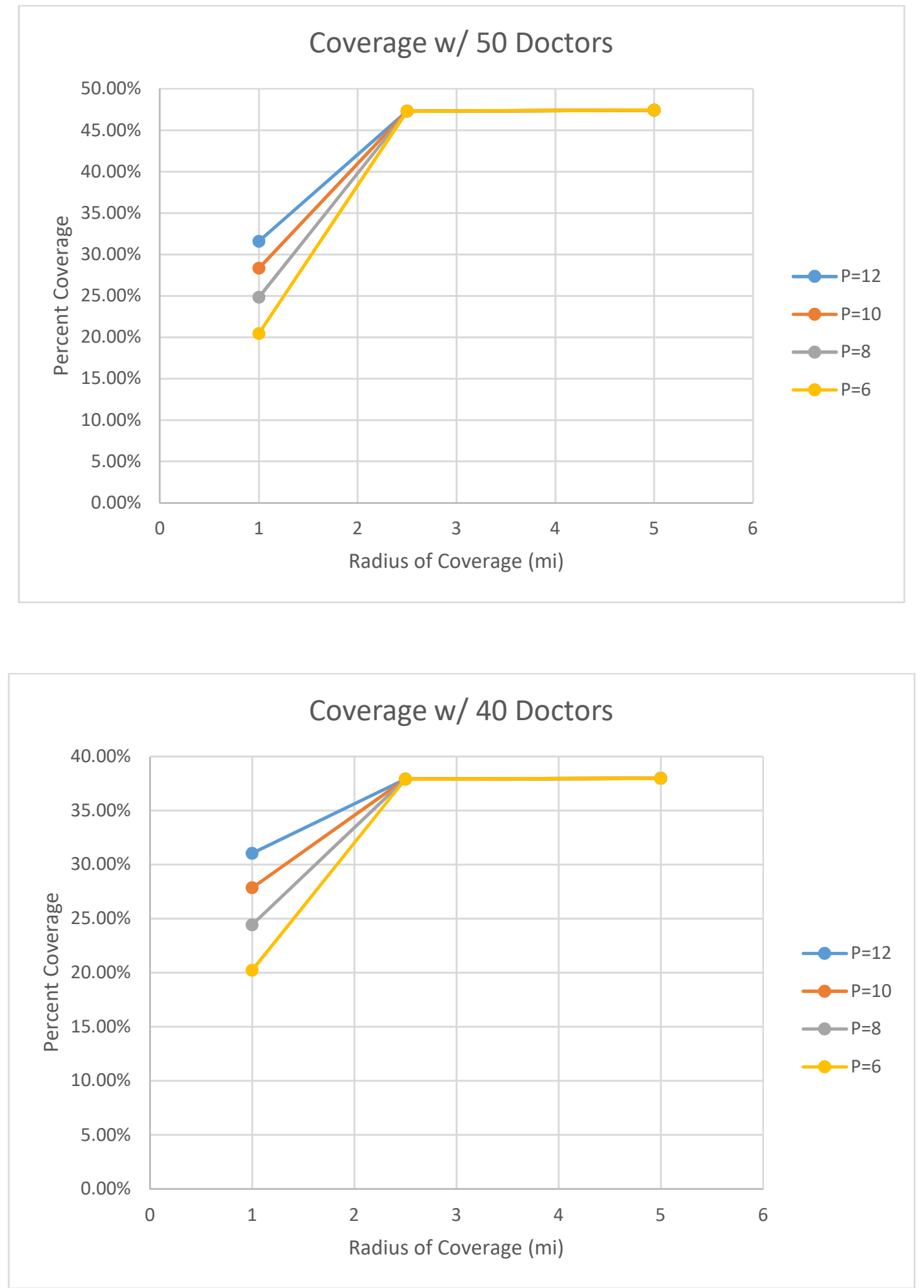

Figure 10: Coverage by number of doctors at fixed radii 


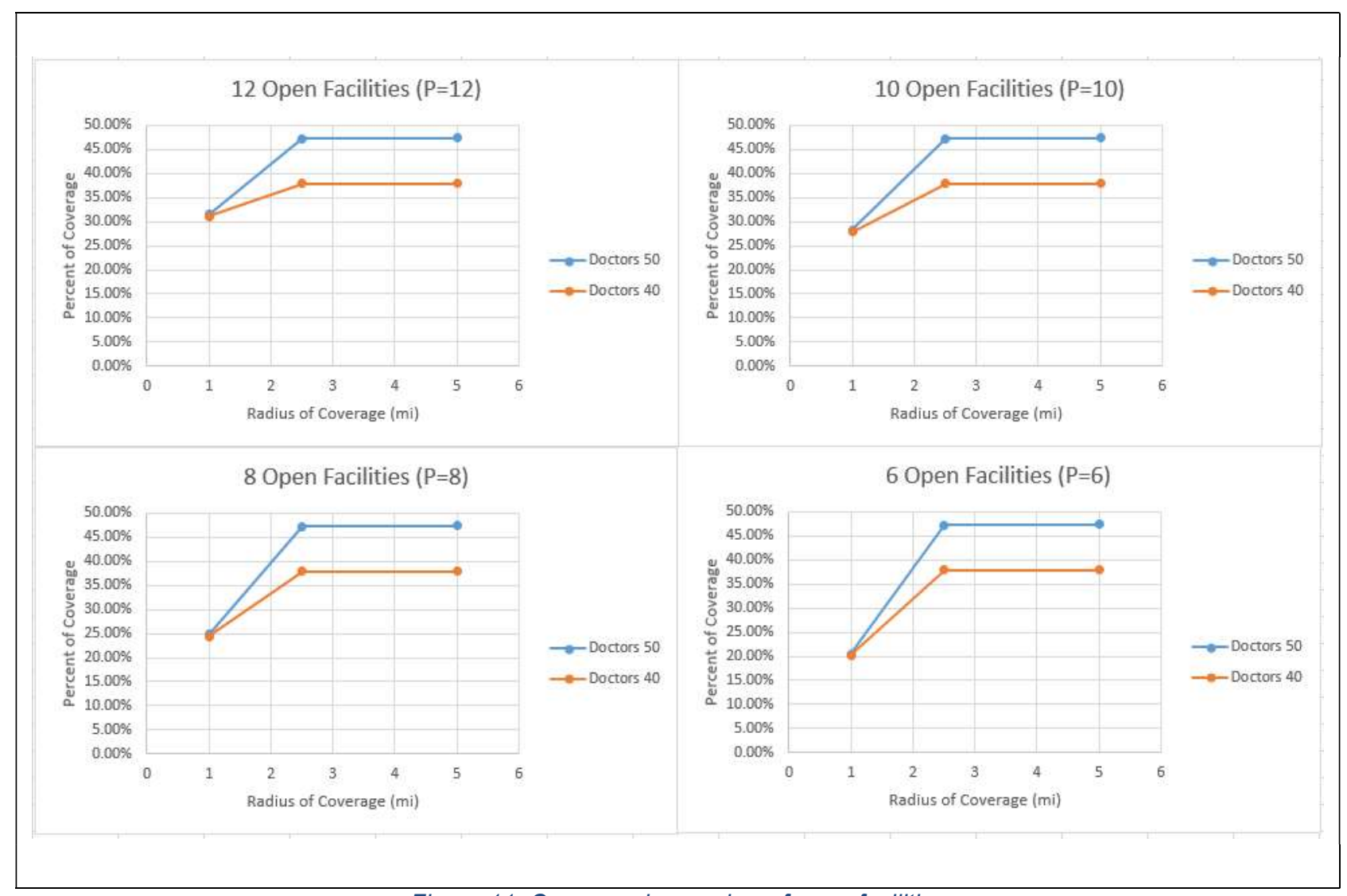

Figure 11: Coverage by number of open facilities

\section{Implications}

\subsection{Run Times}

Run times tended to increase with an increase in parameters. The run times for radii of coverage of 5 miles were greater than those of 2.5 miles and 1 mile (see figure 7). Additionally, run times for 2.5 miles were greater than those of 1 mile. Also, run times for 50 doctors were greater than those for 40 doctors of the same number of facilities and radii of coverage. A reason for this is the data matrix is greater for 50 doctors than for 40 doctors. However, no clear trend exists for the run times when analyzing simply by number of facilities to open. The longest run times for radii of 1 mile occurred for 50 doctors at 10 open facilities and for 2.5 miles at 50 doctors but with 8 open facilities. Lastly, the longest run time for radii of 5 miles occurred at 50 doctors and 6 open facilities. A possible reason is that at the larger radii more analysis is required when the facilities are fewer because of the fewer combinations of overlap of coverage as compared to opening more facilities. This longest run time was a little over 1600 seconds (26 minutes). This is a reasonable wait time for results. However, the implication is that when more parameters are adjusted the run times could exceed this reasonable time frame. 


\subsection{Ways to Increase Coverage}

If budget and resources allow, the best way to increase coverage is to staff 50 doctors any number of open facilities. The results show that at 5 miles of coverage and 50 doctors the percent of coverage converged to $47.43 \%$ coverage for 6 to 12 open facilities (see figure 10). For 40 doctors, the values converged to $37.98 \%$ coverage. Additionally, the increase of 2.5 miles to 5 miles only showed a $0.13 \%$ increase in coverage for 50 doctors and $0.06 \%$ increase for 40 doctors. This suggests that the number of doctors and not the number of facilities is the limiting factor. For 1 mile radius of coverage, the number of facilities is more significant. For both 50 and 40 doctors, the percent of coverage ranges from nearly $20 \%$ to $32 \%$ for 6 to 12 open facilities.

The implication is that the best way to increase coverage is dependent on what the expectation of travel distance is. If the expectation is to maintain 1 mile radius of coverage then the choice of staffing 50 or 40 doctors is insignificant for any number of open facilities. Therefore, for 1 mile of radius staff 40 doctors at 12 facilities for $32 \%$ coverage. This assumes that staffing 40 doctors cost less than staffing 50 doctors. If the expectation is to have an increased radius of coverage, then there exists an insignificant difference in coverage between 2.5 miles and 5 miles for any number of open facilities. Consequently, for either 2.5 miles or 5 miles, staff 50 doctors at 6 open facilities for $47 \%$ coverage. This assumes that 6 open facilities costs less than opening more facilities.

\subsection{Facilities to Open}

The results showed that some facilities were selected as optimal locations more than others. For example, the Division St. community center (index 9) was selected 19 of the 24 trials while the Killingsworth St. community center (index 22) was never selected (see Appendix A). If the radii are considered variable between 1 mile 5 miles and the doctors variable between 40 and 50 doctors, the facilities that were selected most often constitute the optimal locations to open. There were 5 facilities selected over $50 \%$ of the trials (see figure 12). The last facility to open to reach the minimum of 6 facilities is the SW Capitol Highway community center (index 10). It had a count of 12 selections which equals $50 \%$ of the trials. Additionally, the top five facilities favor the north and east quadrants of Portland. The SW Capitol Highway center is located in SW Portland and extends the medical coverage to that section of the city. 


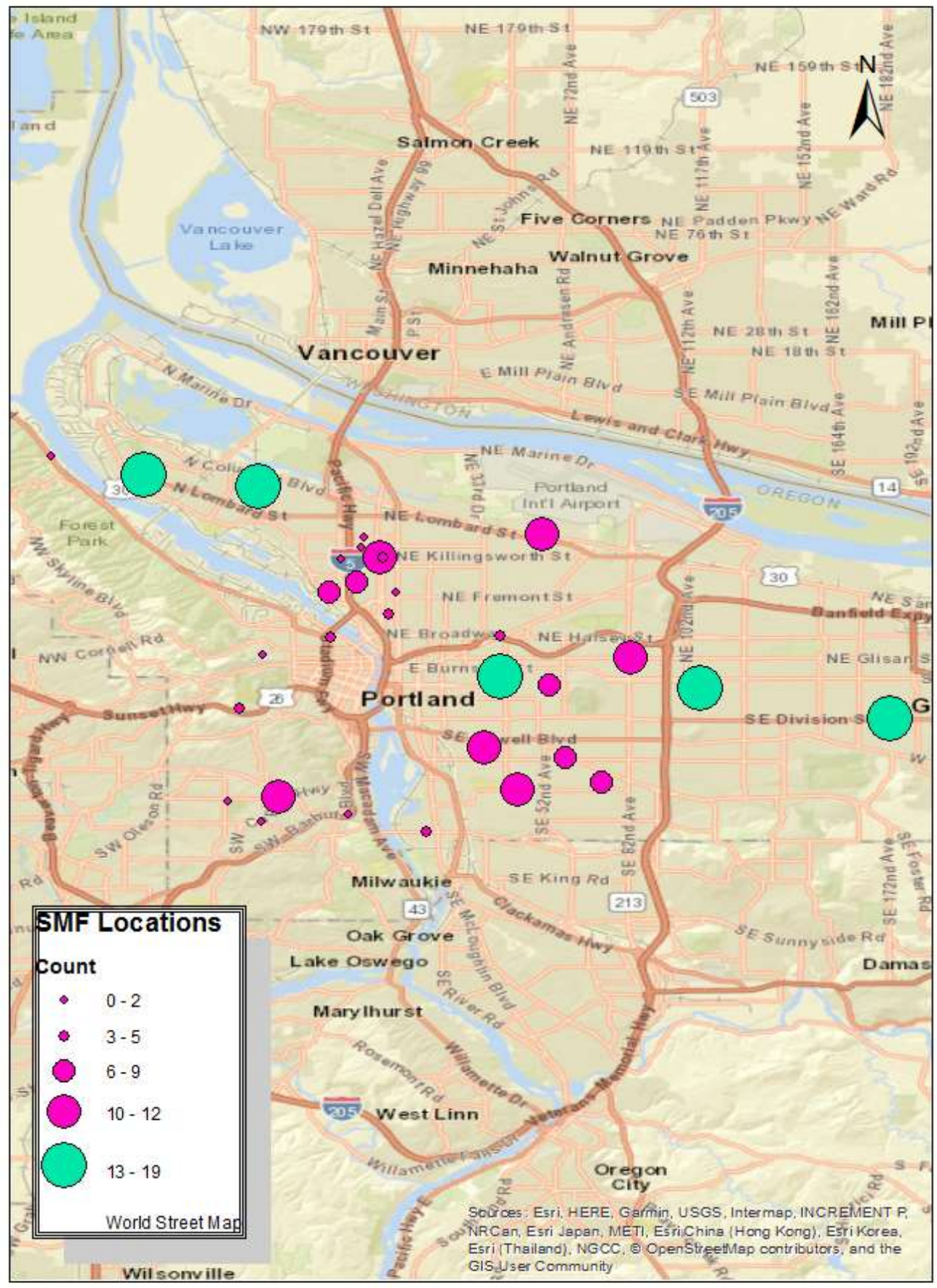

Figure 12: Top facilities to open 


\section{Conclusion}

Engineers have an ethical obligation to uphold public safety and are responsible for the wellbeing of all members of the public. In the case of transportation engineers, this responsibility can take the form of creating better access between individuals and medical care. Access to medical care is not uniform across all demographic populations. The disparity in healthcare access can be remedied or to a certain degree alleviated by the decisions and analysis of engineers. The results of the analysis presented herein showed that medical coverage could be increased by $47 \%$. The coverage is attained by converting parts of existing structures (community centers) into free satellite medical facilities. The facilities are not as robust as hospitals and require minimal staffing; thus, they are a more economical solution than new full-fledged clinics. The model presented in this work is one example of a potential solution to addressing the disparity in Portland, OR and more work is required to fully alleviate the rising burdens of healthcare and travel costs.

\section{Future Research}

- Inclusion of transit distances and times obtained through Google Maps Distance API or equivalent software.

- Cost analysis to determine which is more economical between the choice of staffing more doctors or opening more facilities.

- Increase the number of services and specialties of medical personnel to be more realistic.

- Radii of Coverage parameter to ensure minimal overlap. 


\section{References}

1. "Code of Ethics." American Society of Civil Engineers (ASCE), www.asce.org/code-of-ethics/.

2. Lucas, K., "Transport and Social Exclusion: Where are we now?" Transport Policy 2012, doi: $10.1016 / j$.tranpol.20012.01.013

3. Miller, J., "Paying for Health Care with Time." Harvard Gazette, Harvard Medical School Communications, 5 Oct. 2015, news.harvard.edu/gazette/story/2015/10/paying-for-health-carewith-time/.

4. "ATUS News Releases." U.S. Bureau of Labor Statistics, U.S. Bureau of Labor Statistics, www.bls.gov/tus/home.htm.

5. Chauhan, D. "Satellite Medical Facilities Location in Portland, OR." Portland State University, Dec. 2017.

6. "Satellite Clinic." The Free Dictionary, Farlex, medical- dictionary. thefreedictionary. com/ satellite+clinic.

7. "Planning for the Rising Costs of Health Care." Morgan Stanley, www.morganstanley.com /ideas/healthcare-costs.

8. "Oregon Health Insurance Survey: Demographic Information Fact Sheet," Oregon Health Authority, 2015.

9. Weber, A., "Alfred Weber's Theory of the Location of Industries". Edited by Carl J Friedrich, University of Chicago Press, 1929.

10. Revelle, C., et al. "Bibliography for some fundamental problem categories in discrete location science.” Jan. 2007, https://doi.org/10.1016/j.ejor.2006.12.044

11. Daskin, M. S. and L. K. Dean, 2004, "Location of Health Care Facilities," chapter 3 in the Handbook of OR/MS in Health Care: A Handbook of Methods and Applications, F. Sainfort, M. Brandeau and W. Pierskalla, editors, Kluwer, pp. 43-76.

12. Syam, S. \& Cote, M., "A comprehensive location-allocation method for specialized healthcare services." Operations Research for Health Care 1(4). pgs. 73-83. Dec. 2012. 
13. Yong, Teo, and Kiong. "Improving Healthcare Facility Locations in Bamyan, Afghanistan." Calhoun Home, Monterey, California. Naval Postgraduate School, 1 Dec. 2011, calhoun.nps.edu/handle/10945/10703.

14. Guo, Mengyu, et al. "Efficiency Evaluation for Allocating Community-Based Health Services."Communications of the ACM, Computers and Industrial Engineering, 65 (3). pgs 395401. July 2013. doi $>10.1016 /$ j.cie.2013.03.008

15. Shariff, R., et al. "Location allocation modeling for healthcare facility planning in Malaysia." Computers and Industrial Engineering. Elsevier. May 2012.

16. Baray, J. \& Cliquet, G., "Optimizing location through a maximum covering / p meridian hierarchal model: Maternity hospitals in France.” Journal of Business Research 66(1). pgs. 127132. DOI: 10.1016/j.jbusres.2012.09.003

17. Galvao, R., "Uncapacitated facility location problems: contributions." Revista Brasileira De Hematologia e Hemoterapia, Associação Brasileira De Hematologia e Hemoterapia, www.scielo.br/scielo.php?script=sci_arttext\&pid=S0101-74382004000100003.

18. "Reproductive Health." Centers for Disease Control and Prevention, Centers for Disease Control and Prevention, 2 Jan. 2018, www.cdc.gov/reproductivehealth/maternalinfanthealth/infantmortality.htm.

19. "Building U.S. capacity to review and prevent maternal deaths." CDC Foundation, www.cdcfoundation.org/building-us-capacity-review-and-prevent-maternal-deaths.

20. "Reproductive Health." Centers for Disease Control and Prevention, Centers for Disease Control and Prevention, 9 May 2018, www.cdc.gov/reproductivehealth/maternalinfanthealth/pregnancy-relatedmortality.htm.

21. "Postpartum care of the mother and newborn: a practical guide." World Health Organization, Maternal and Newborn Health / Safe Motherhood Unit 1998.

22. "Statistics about diabetes." American Diabetes Association, www.diabetes.org/diabetesbasics/statistics/.

23. "Number of Diabetes Deaths per 100,000 Population by Race/Ethnicity." The Henry J. Kaiser Family Foundation, the Henry J. Kaiser Family Foundation, 20 Mar. 2018.

24. "The basics: Relative Value Units (RVUs)." National Health Policy Forum. George Washington University Jan. 2012. 
25. Newport, F., and G. Gates. "San Francisco Metro Area Ranks Highest in LGBT Percentage.”Gallup.com, 20 Mar. 2015, news.gallup.com/poll/182051/san-francisco-metro-arearanks-highest-lgbt-percentage.aspx.

26. Leonhardt, D. and Miller, C., "The Metro Areas with the Largest, and Smallest, Gay Populations." The New York Times, The New York Times, 20 Mar. 2015, www.nytimes.com/2015/03/21/upshot/the-metro-areas-with-the-largest-and-smallest-gaypopulation.html.

27. Hannah-Jones, N., "Number of Oregon Same-Sex Households Grows Nearly 68 Percent, According to Census Analysis." OregonLive.com, OregonLive.com, 28 Sept. 2011, www.oregonlive.com/pacific-northwest-news/index.ssf/2011/08/oregon_samesex_households_grow_nearly_60_percent_according_to_us_census.html.

28. "RLIS Discovery.” RLIS Discovery: Home, rlisdiscovery.oregonmetro.gov/.

29. "Calculating Longitude Length in Miles?” Geographic Information Systems Stack Exchange, gis.stackexchange.com/questions/142326/calculating-longitude-length-in-miles.

30. "Vision Zero." PBOT Portland Bureau of Transportation.

https://www.portlandoregon.gov/transportation/40390

31. "FHWA NHTS brief: Mobility challenges for households in poverty." 2009 National Household Travel Survey. https://nhts.ornl.gov/briefs/PovertyBrief.pdf

32. "Standard Mileage Rates." Internal Revenue Service, www.irs.gov/taxprofessionals/standard-mileage-rates.

33. Bohannon, R W, and Williams, A., "Normal Walking Speed: a Descriptive Meta-Analysis." Advances in Pediatrics., U.S. National Library of Medicine, Sept. 2011, www.ncbi.nlm.nih.gov/pubmed/21820535. 


\section{Appendix A: Community center coordinates counts of opening across all trials}

\begin{tabular}{|c|c|c|c|c|}
\hline Latitude & Longitude & Count & Community Centers & Index \\
\hline 45.50513 & -122.4856 & 19 & 17229 SE Division St, Portland OR 97236 & 9 \\
\hline 45.51581 & -122.5532 & 17 & 740 SE 106th Ave, Portland OR 97216 & 26 \\
\hline 45.51988 & -122.6246 & 15 & 3756 SE Oak St, Portland OR 97214 & 18 \\
\hline 45.59224 & -122.7522 & 15 & 8427 N Central St, Portland OR 97203 & 29 \\
\hline 45.58773 & -122.7114 & 14 & 9009 N Foss Ave, Portland OR 97203 & 25 \\
\hline 45.47706 & -122.704 & 12 & 6651 SW Capitol Highway, Portland OR 97219 & 10 \\
\hline 45.52681 & -122.5785 & 12 & 8219 NE Glisan St, Portland OR 97220 & 27 \\
\hline 45.57084 & -122.6096 & 11 & 5135 NE Columbia Blvd, Portland, OR 97218 & 1 \\
\hline 45.49457 & -122.6305 & 11 & 3350 SE Francis St, Portland OR 97202 & 16 \\
\hline 45.47978 & -122.6188 & 11 & 5905 SE 43rd Ave, Portland OR 97206 & 30 \\
\hline 45.56226 & -122.6676 & 10 & 5325 N Williams Ave, Portland OR 97217 & 12 \\
\hline 45.49132 & -122.6014 & 9 & 6036 SE Foster Rd, Portland OR 97206 & 11 \\
\hline 45.48244 & -122.5887 & 9 & 5530 SE 72nd Avenue, Portland OR 97206 & 13 \\
\hline 45.55033 & -122.6857 & 8 & 3839 N Melrose Drive, Portland OR 97227 & 19 \\
\hline 45.55366 & -122.6759 & 7 & 4115 N Mississippi Ave, Portland, OR 97217 & 2 \\
\hline 45.51674 & -122.6071 & 7 & 5441 SE Belmont St, Portland, OR 97215 & 4 \\
\hline 45.46482 & -122.6513 & 5 & 1436 SE Spokane St, Portland OR 97202 & 28 \\
\hline 45.53393 & -122.6854 & 4 & 1542 NW 14th Avenue, Portland, OR 97209 & 3 \\
\hline 45.54217 & -122.6649 & 4 & 77 NE Knott St, Portland OR 97212 & 20 \\
\hline 45.53458 & -122.6247 & 3 & 1630 NE 38th Ave, Portland OR 97232 & 0 \\
\hline 45.56252 & -122.6666 & 3 & 14 NE Killingsworth Street, Portland OR 97211 & 5 \\
\hline 45.5085 & -122.7179 & 3 & 4015 SW Canyon Road, Portland OR 97221 & 17 \\
\hline 45.47581 & -122.7221 & 2 & 6820 SW 45th Ave, Portland OR 97219 & 21 \\
\hline 45.5278 & -122.7097 & 2 & 653 NW Culpepper Terrace, Portland OR 97210 & 24 \\
\hline 45.5986 & -122.7853 & 1 & 10614 NW St. Helens Rd, Portland OR 97231 & 6 \\
\hline 45.55022 & -122.6619 & 1 & 3801 NE Martin Luther King Jr. Blvd, Portland OR 97212 & 8 \\
\hline 45.47095 & -122.679 & 1 & 68 SW Miles St, Portland OR 97219 & 23 \\
\hline 45.56617 & -122.6746 & 0 & 5940 North Albina St, Portland OR 97217 & 7 \\
\hline 45.56956 & -122.6736 & 0 & 700 N Rosa Parks Way, Portland OR 97217 & 14 \\
\hline 45.46818 & -122.71 & 0 & 7688 SW Capitol Hwy, Portland OR 97219 & 15 \\
\hline 45.56175 & -122.6819 & 0 & 2 N Killingsworth St, Portland OR 97217 & 22 \\
\hline
\end{tabular}




\section{Appendix B: Python Code and Script}

\#\# Satellite Medical Facility Location - basic Coverage Objective

import numpy as $\mathrm{np}$

from gurobipy import *

import timeit

file1 = open("p12.R1mi.do50.distx+y.txt","w")

run $=\mathrm{np}$. arange $(1,2)$

file1.write("Run Number, p, Radius of Coverage, Time of Exceution, Optimal Value, Index where facility is opened, $\ln "$ )

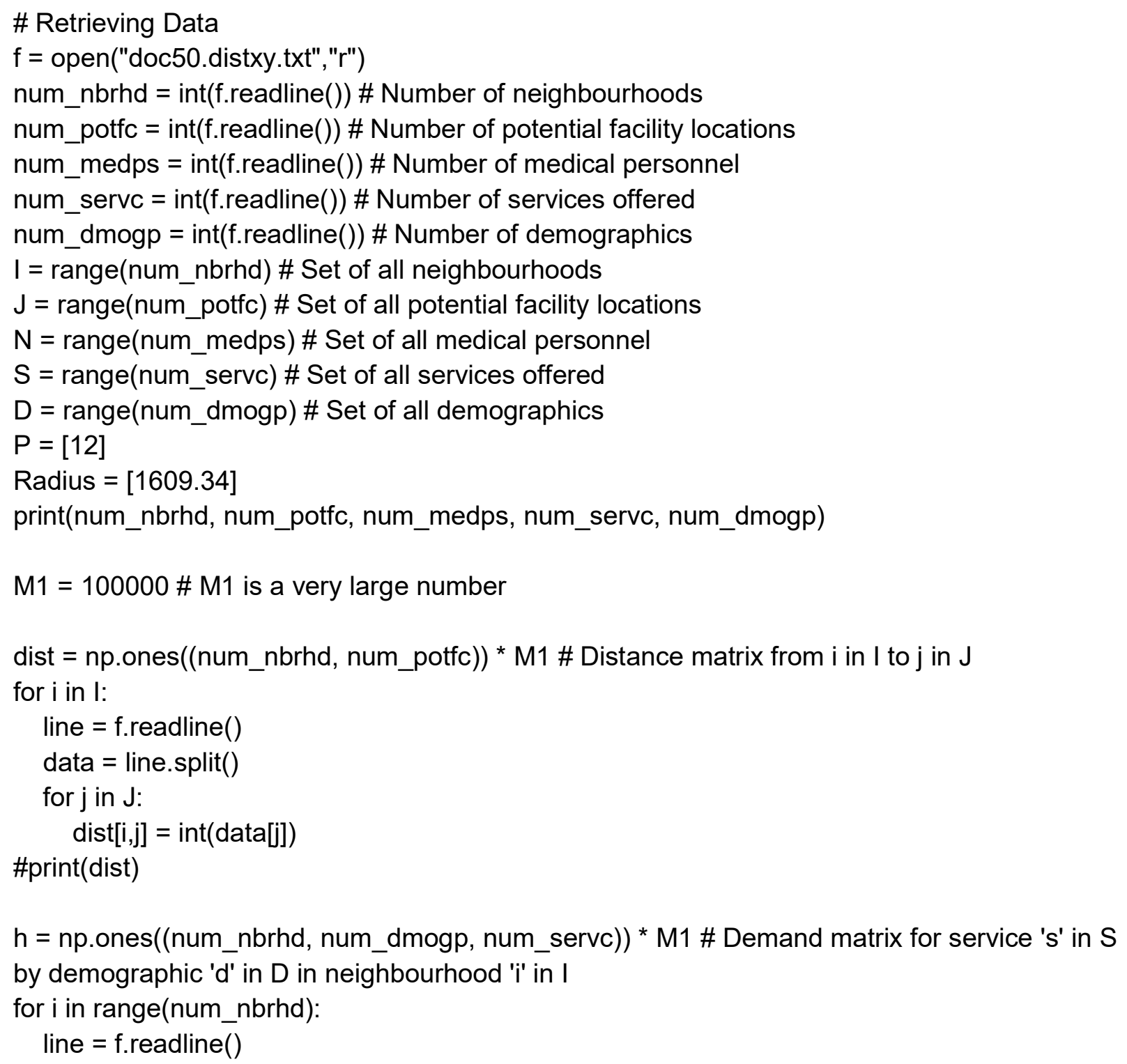




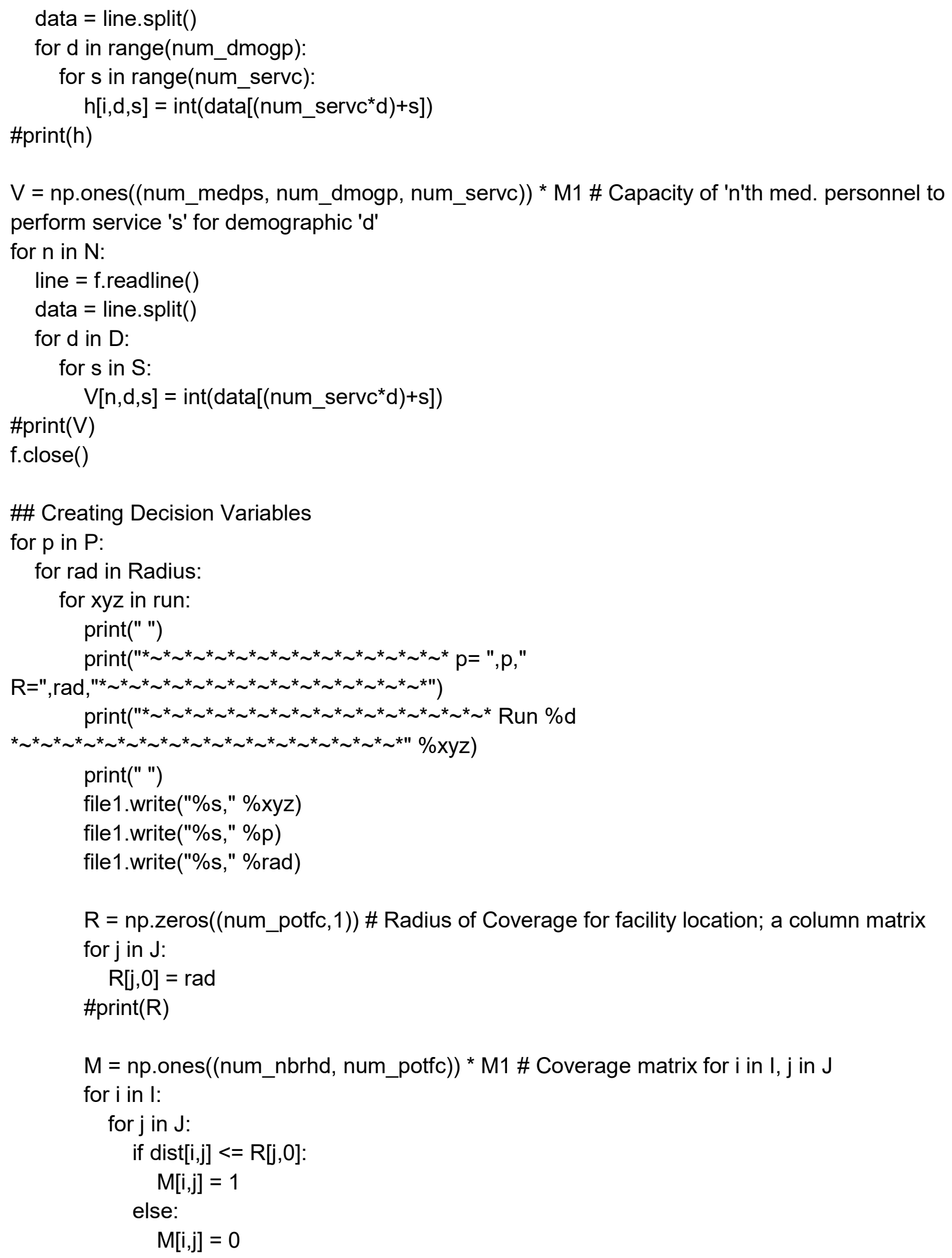


$\mathrm{m}=$ Model ()

$\# \# Y_{j} j$ : if facility is opened at location 'j' or not

$Y=[]$

for $\mathrm{j}$ in $\mathrm{J}$ :

Y.append $($ m.addVar(vtype=GRB.BINARY, name="Y[\%d]" \% j))

\#\# X_jids : fraction of demand of a service 's' of demographic 'd' in neighbourhood 'i' satisfied at location ' $\mathrm{j}$ '

$X=m \cdot \operatorname{addVars}(J, I, D, S, I b=0, u b=1$, name="X")

\#\# U_ids : Unmet demand of a service 's' of demographic 'd' in neighbourhood 'i'

$\mathrm{U}=\mathrm{m} \cdot \operatorname{add} \operatorname{Vars}(\mathrm{I}, \mathrm{D}, \mathrm{S}, \mathrm{Ib}=0, \mathrm{ub}=1$, name="U")

\#\# B_in : If a medical personnel ' $n$ ' is stationed at location ' $\mathrm{j}$ '

$\mathrm{B}=\mathrm{m} \cdot \operatorname{addVars}(\mathrm{J}, \mathrm{N}, \mathrm{vtype}=\mathrm{GRB} \cdot \mathrm{BINARY}$, name="B")

\#\# W_jnds : Fraction of time spent by ' $n$ 'th medical personnel on service 's' of demographic 'd' at facility location ' $j$ '

$\mathrm{W}=\mathrm{m} \cdot \operatorname{add} V \operatorname{ars}(\mathrm{J}, \mathrm{N}, \mathrm{D}, \mathrm{S}, \mathrm{Ib}=0, \mathrm{ub}=1$, name="W")

\#\# Objective function

\#\# Eq1: Minimize total unmet demand

obj = quicksum $\left(\left(h[i, d, s]{ }^{*} U[i, d, s]\right)\right.$ for $i$ in I for $d$ in $D$ for $s$ in $\left.S\right)$

m.setObjective(obj, GRB.MINIMIZE)

\#\# Constraints

\#\# Eq2: Fraction of demand satisfied + Fraction of unmet demand $=1$

m.addConstrs $\left(\left(\left(q u i c k s u m\left(X[j, i, d, s]^{*} M[i, j]\right.\right.\right.\right.$ for $j$ in $\left.\left.J\right)+U[i, d, s]==1\right)$ for $i$ in I for $d$ in $D$ for $s$ in S), name="Eq2")

\#\# Eq3: Demand - Capacity <= 0

m.addConstrs $\left(\left(\left(\right.\right.\right.$ quicksum $\left(X[j, i, d, s]^{\star} h[i, d, s]^{\star} M[i, j]\right.$ for i in I) - quicksum(W[j,n,d,s] ${ }^{\star} V[n, d, s]$

for $\mathrm{n}$ in $\mathrm{N}$ ) $<=0$ ) for $\mathrm{j}$ in $\mathrm{J}$ for $\mathrm{d}$ in $\mathrm{D}$ for $\mathrm{s}$ in $\mathrm{S}$ ), name="Eq3")

\#\# Eq4: Facility Opening Limit

m. addConstr((quicksum(Y[j] for $\mathrm{j}$ in J) == p), name="Eq4")

\#\# Eq5: Medical Personnel completes all his work at 1 facility location at which he is assigned

m.addConstrs (( (quicksum $(W[j, n, d, s]$ for $d$ in $D$ for $s$ in $S)==B[j, n])$ for $j$ in $J$ for $n$ in $N)$, name="Eq5") 
\#\# Eq6: Medical Personnel is assigned only to one facility m.addConstrs (( (quicksum(B[j,n] for $\mathrm{j}$ in $\mathrm{J})==1$ ) for $\mathrm{n}$ in $\mathrm{N})$, name="6")

\#\# Eq6: Basic inequality constraint about work done by Medical personnel m.addConstrs (( $(W[j, n, d, s]<=B[j, n])$ for $j$ in $J$ for $n$ in $N$ for $d$ in $D$ for $s$ in $S)$, name="Eq7a") m.addConstrs (((B[j,n]<= Y[j]) for $\mathrm{j}$ in $\mathrm{J}$ for $\mathrm{n}$ in $\mathrm{N})$, name="Eq7b")

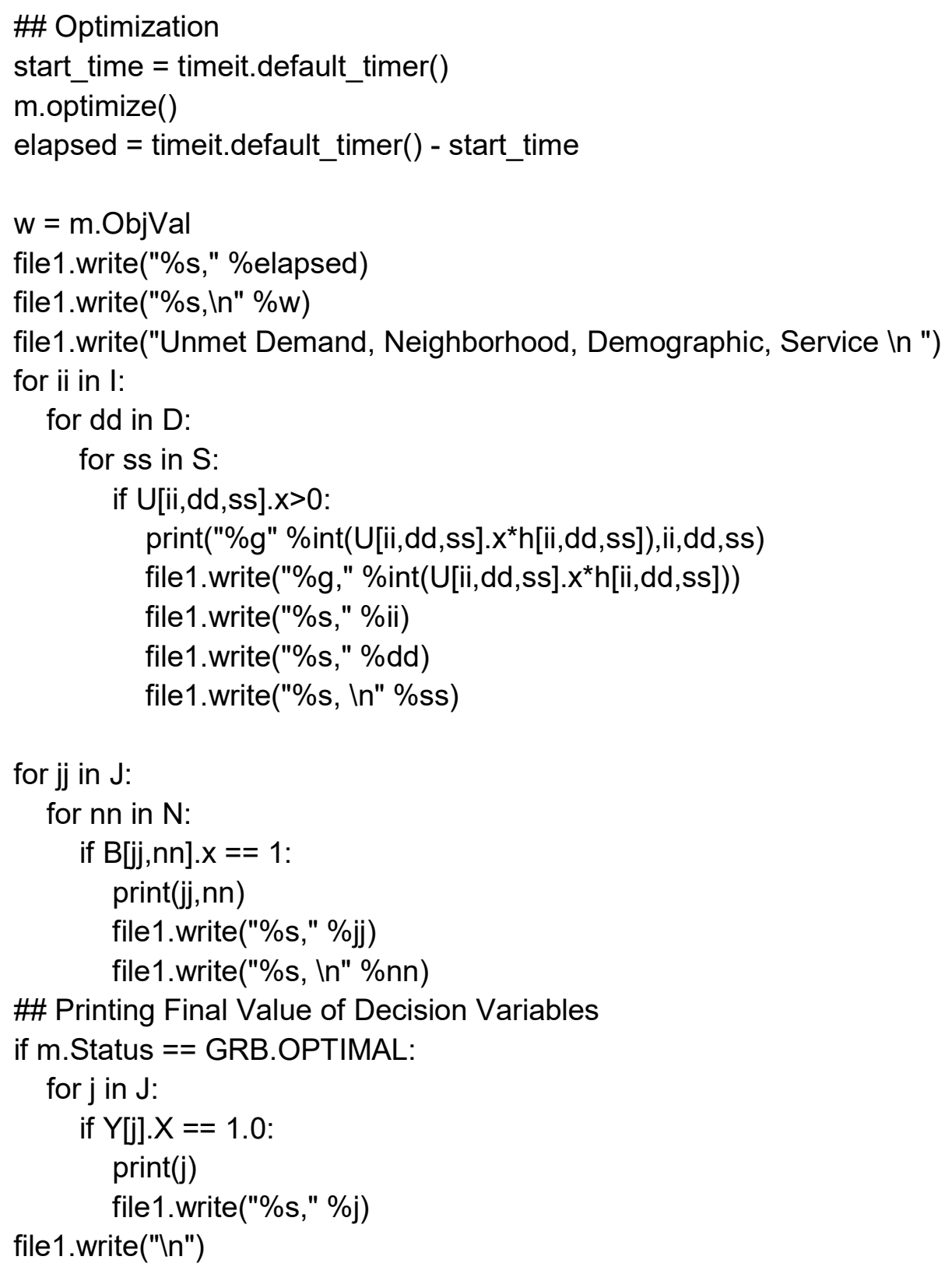

file1.close() 